\title{
Electric Boosting and Energy Recovery Systems for Engine Downsizing
}

\author{
Mamdouh Alshammari ${ }^{1,2}$, Fuhaid Alshammari ${ }^{2}$ and Apostolos Pesyridis ${ }^{1, *}$ (i) \\ 1 Centre of Advanced Powertrain and Fuels (CAPF), Department of Mechanical, Aerospace and Civil \\ Engineering, Brunel University London, Middlesex UB8 3PH, UK; Mamdouh.Alshammari@brunel.ac.uk \\ 2 Department of Mechanical Engineering, University of Hai'l, Hail 55476, Saudi Arabia; \\ fu.alshammari@uoh.edu.sa \\ * Correspondence: a.pesyridis@brunel.ac.uk
}

Received: 31 October 2019; Accepted: 4 December 2019; Published: 6 December 2019

\begin{abstract}
Due to the increasing demand for better fuel economy and increasingly stringent emissions regulations, engine manufacturers have paid attention towards engine downsizing as the most suitable technology to meet these requirements. This study sheds light on the technology currently available or under development that enables engine downsizing in passenger cars. Pros and cons, and any recently published literature of these systems, will be considered. The study clearly shows that no certain boosting method is superior. Selection of the best boosting method depends largely on the application and complexity of the system.
\end{abstract}

Keywords: engine downsizing; electrically assisted turbocharger; electric supercharger; e-turbo; waste heat recovery; turbocharging; supercharging; turbocompounding; organic Rankine cycle

\section{Introduction}

Although internal combustion engines are getting more efficient nowadays, still the major part of fuel energy is transformed into wasted heat. In terms of harmful exhaust emissions, the transportation sector is responsible for the one-third of $\mathrm{CO}_{2}$ emissions worldwide and approximately $15 \%$ of the overall greenhouse gas emissions [1]. Moreover, owing to the limited amount of fossil fuels, prices fluctuate significantly, with consistent general rising trends, resulting in economic issues in non-oil-producing countries. For example, fuel prices have continually increased, from 60 pence/litre in 1997 to 120 pence/litre in 2013 in the United Kingdom [2].

Reduction of exhaust gas emissions is gaining great attention. Recently, organic Rankine cycles (ORC) have been intensively applied [3]. Alshammari et al. [4,5] tested the ORC system as a bottoming cycle in heavy-duty diesel engines. The results were promising with $3 \%$ reduction in engine exhaust gases and $6 \mathrm{~kW}$ generated power. In a subsequent study, Alshammari and Pesyridis [6] improved the performance of the ORC by testing the coupled engine-ORC system at low-temperature cooling water and integrating the custom-designed radial inflow turbine detailed in [7]. Lowering the cooling water temperature resulted in higher enthalpy drop and hence higher electrical power $(9 \mathrm{~kW}$ compared to 6 $\mathrm{kW}$ in the previous testing). However, the implementation of ORC in modern passenger cars requires additional features to achieve a compact integration and controllability in the engine. Moreover, vehicles gain extra weight when coupled to an ORC system, which results in higher fuel consumption [8].

Another waste heat recovery technology of note in internal combustion engines is thermoelectric generation (TEG). Thermoelectric generators convert some of the waste heat of an internal combustion engine (IC) into electricity using the Seebeck effect. However, this technology has three main challenges. Firstly, it has generally exhibited a substantially inferior efficiency, typically less than $4 \%$ [9]. The second challenge is the bigger size of the radiator and extended piping to the exhaust manifold [10]. Thirdly, 
thermoelectric generators are not mature yet and some efficient materials are yet to be manufactured [11]. However, new nano-crystalline or nano-wire thermoelectric materials are currently in the development stage to improve the conversion efficiency of thermoelectric generators.

Therefore, automotive vehicles, especially passenger cars, need more advanced and practical technologies in order to improve the engine performance in terms of emissions and fuel consumption. The most competent emission reduction technology today is engine downsizing coupled with boosting technology. Thirouard et al. [12] defined engine downsizing as the use of a 'small-capacity engine operating at high specific engine loads to achieve low fuel consumption'. The main advantages of downsizing technology are a significantly increased power and torque for the engine without increasing the capacity of the engine. Moreover, fuel consumption is reduced primarily by decreasing the friction losses associated with reduced engine size and improving the efficiency of an engine when running at high loads [12]; with small intake throttling, pumping losses are lessened. Petitjean et al. [13] described the latter aspect as effectively 'moving the best fuel economy island [of the engine] close to the steady state road load condition', or alternately as avoiding conducting the operation in the area with huge pumping losses. With regard to friction, sliding surface friction is typically reduced by decreasing the piston-ring-to-cylinder contact area (associated with a reduced number of cylinders and/or decreased bore and stroke) and the swept area of crankshaft journal bearings.

This effect is illustrated in Figure 1, which compares the brake specific fuel consumption (BSFC) map of a $2.6 \mathrm{~L}$ naturally aspirated gasoline engine and a $1.8 \mathrm{~L}$ turbocharged downsized engine. The BSFC of downsized engine is consistently low along the steady state road load curve.

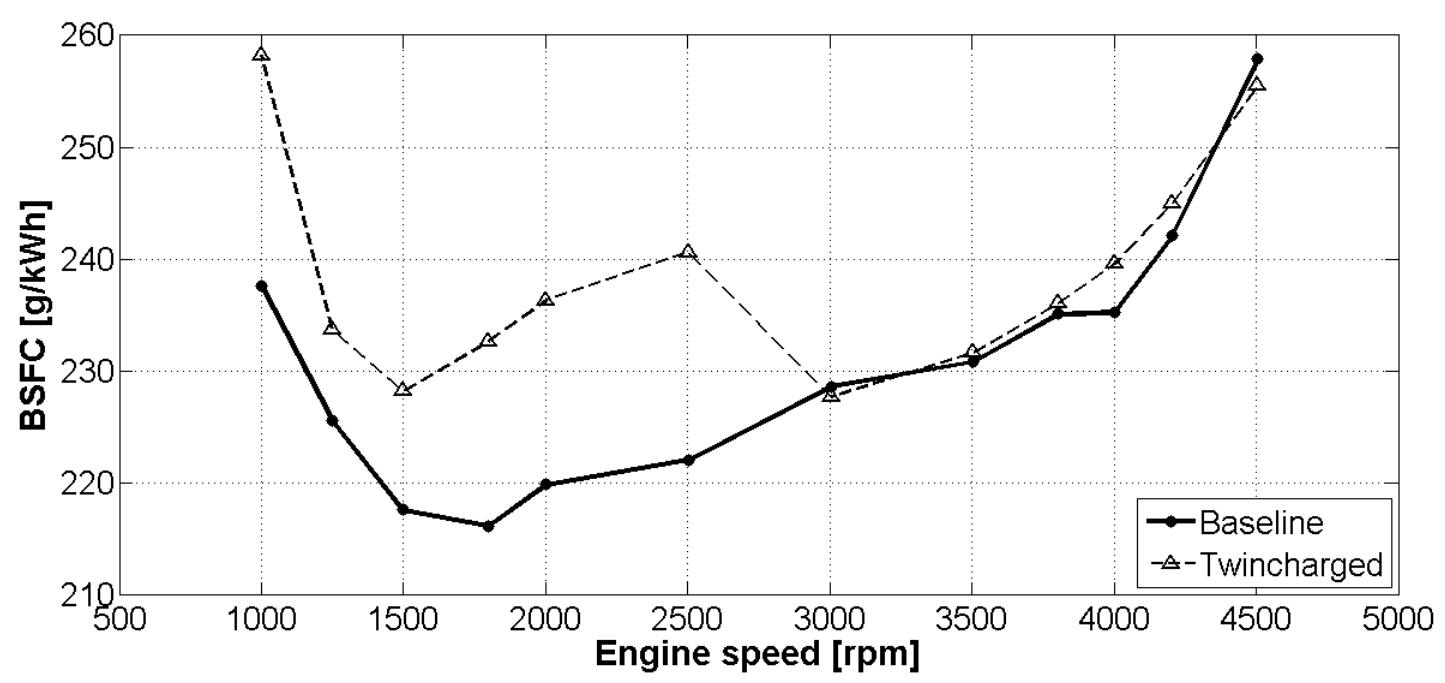

Figure 1. Comparison of brake specific fuel consumption (BSFC) maps of naturally aspirated and downsized engines [14].

In this example, full-load performance potential is typically maintained through pressure charging (supercharging) to facilitate downsizing [15-18]. In conjunction with turbocharging, direct fuel injection and variable valve timing for inlet and exhaust valves can aid in the downsizing for gasoline engines [15]. According to Turner et al. [19], gasoline direct injection (GDI) produces high compression ratios for improved thermal efficiency because of its charge cooling effects, and variable valve timing (inlet and exhaust) increases scavenging and reduces part-load throttling losses. These technologies have been combined and adopted by various manufacturers, including Ford [20] and Romeo [21], to reduce emissions through engine downsizing. Fiat has removed the throttle (throttling losses) and its 'MultiAir' electrohydraulic valve actuation technology [22]. Other technologies synergistic with downsizing, including spray-guided direct injection [23], have been implemented by Mercedes [24] while variable compression ratio has not yet attained production $[25,26]$. 
The basis for increased specific engine output, which is crucial to engine downsizing, is the definition of fundamental engine performance parameters. Heywood [27] derived the equation for specific power as follows:

$$
\frac{P}{A_{p}}=\frac{\eta_{f} \eta_{v} S_{p}^{-} Q_{H V} \rho_{a, i n}\left(\frac{F}{A}\right)}{4}
$$

where $\mathrm{P}$ is power $(\mathrm{W}), A_{p}$ is the total piston area $\left(\mathrm{m}^{2}\right), \eta_{f}$ is fuel conversion efficiency, $\eta_{v}$ is volumetric efficiency, and $S^{-}{ }_{p}$ is mean piston speed $(\mathrm{m} / \mathrm{s}) . Q_{H V}$ is fuel heating value $(\mathrm{J} / \mathrm{kg}), \rho_{a, i n}$ is the inlet air density, and $(F / A)$ is fuel-air ratio.

In this equation, the following factors directly affecting the performance of an engine are considered. Increasing any of them will also increase the engine performance (provided all other factors are equal):

1. Fuel conversion efficiency (inversely proportional to specific fuel consumption);

2. Volumetric efficiency;

3. Inlet air density;

4. Maximum fuel/air ratio that can be usefully burned in the engine;

5. Mean piston speed.

Engine downsizing targets points 2 and 3 in this list and point 1 of at least under 'real-world' (part load) driving conditions, if not full-load conditions.

In this paper, the boosting requirements are discussed. In addition, the variety of boosting systems are presented and the suitability of each one is analysed in relation to the engine requirements and in comparison to the other boosting systems.

\section{Downsizing Enablers}

This section briefly presents various types of turbines and compressors integrated in different boosting systems.

\subsection{Compressor Technologies}

Two main configurations of compressors, namely, single-stage and multistage, are discussed in terms of their applications and operating conditions. In order to meet the requirements of continuously enhanced brake mean effective pressure (BMEP), the turbocharger boost pressure ratio should be increased as shown in Figure 2.

It is worth mentioning that BorgWarner has developed water-cooled compressor housing. For high specific power outputs, an extreme boost pressure and pressure ratio are required. However, a high-pressure ratio also leads to a high compressor outlet temperature. Therefore, the water-cooled compressor housing is integrated in order to reduce the compressor outlet temperature and ultimately to prevent the coking of oil in the compressor volute and the charge air cooler [28]. 


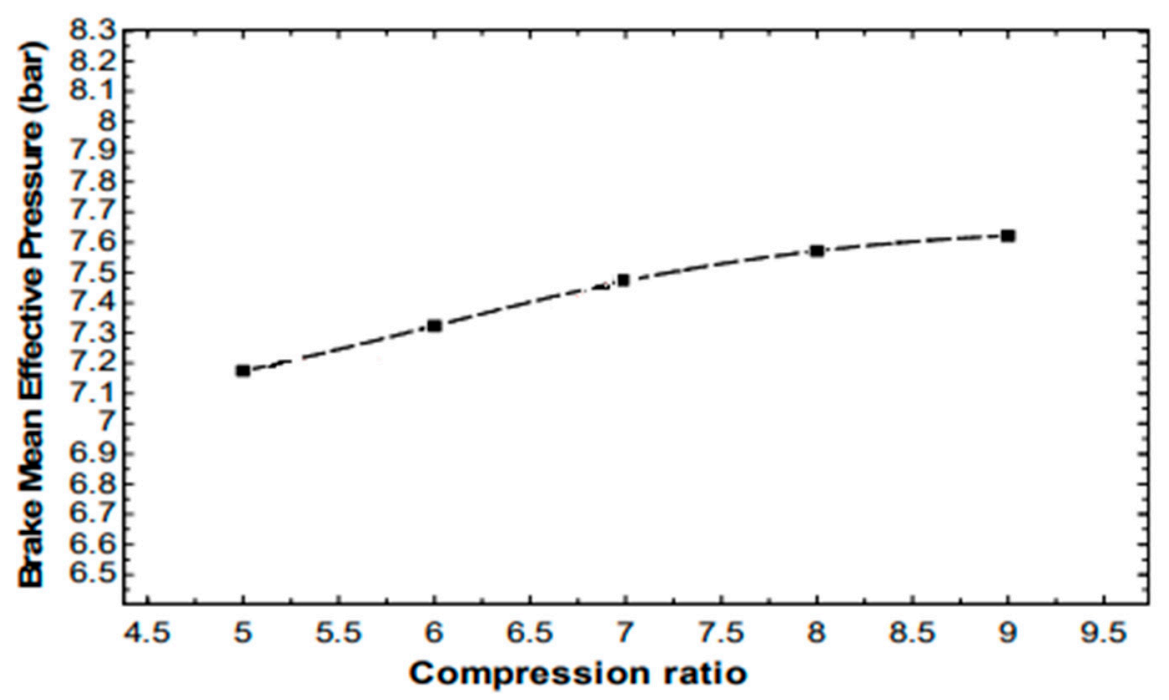

Figure 2. Required boosting pressure ratio at different BMEP [29].

\subsubsection{Single Stage Compressor}

Operating with a high-pressure ratio in single stage compressor in Figure 3 results in transonic flow and strong tip clearance losses. However, at a pressure ratio of 4 , the aforementioned challenges can be overcome by applying stability enhancement methods such as air injection at the impeller inducer/diffuser inlet, adjustable inlet guide vanes, and fluctuating plate at the compressor outlet. The aforementioned methods assist in decreasing the mass flow surge for the compressor. Another method for stability enhancement is the treatment of the compressor casing near the inducer. Figure 4 shows a compressor map with casing treatments. The figure clearly shows the shift of surge limit at low speed operation is more distinct and towards higher mass flow rate.

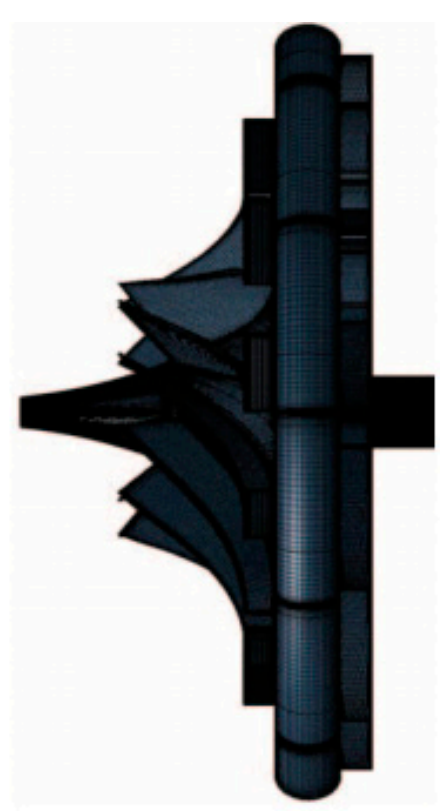

Single Stage Compressor

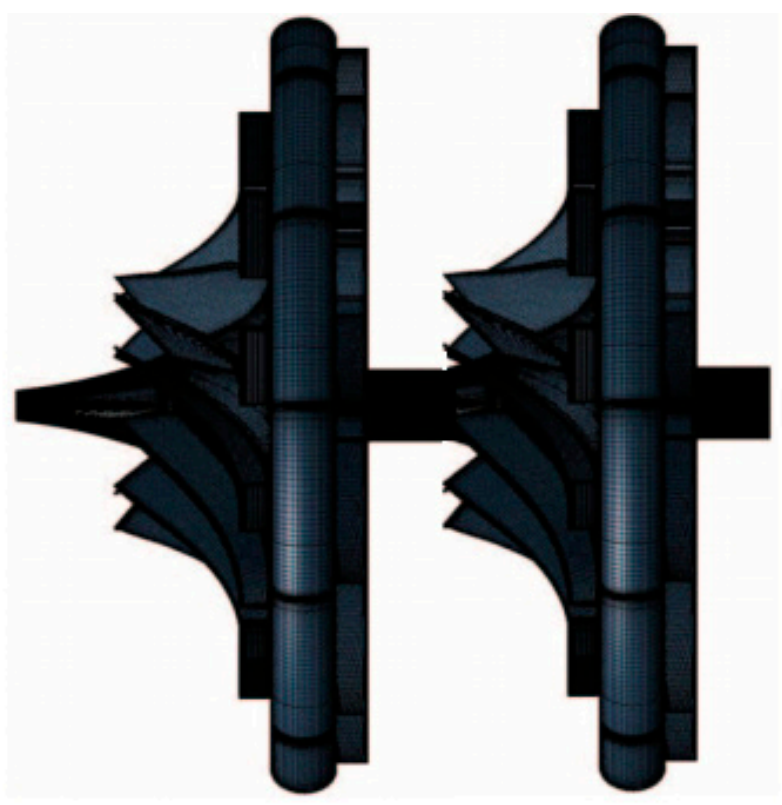

Multistage Compressor

Figure 3. Configurations of single-stage and multistage compressors. 


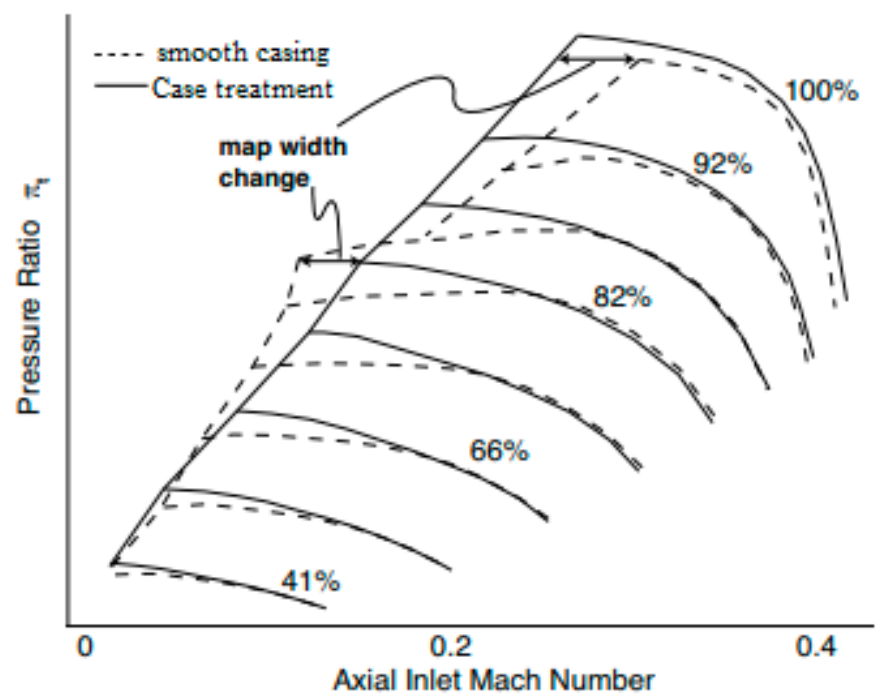

Figure 4. Measured performance of compressors with case treatment [30].

\subsubsection{Multistage Compressor}

The multistage configuration Figure 3 is two compressors connected through a common shaft with the turbine. This configuration is beneficial since the system operates with high boost pressure and low rotational speed and hence lower stress and higher efficiency. However, multistage configuration has drawbacks; the difficulty of matching between the compressors and extra power required by the turbine in order to drive the two compressors.

\subsubsection{Variable Trim Compressor}

A new technology is proposed by Swine and Engeda [31] to modify the impeller design by trimming the impeller. This technology assists in maintaining the efficiency of the compressor high for longer time. This can be achieved by optimizing the hub and shroud control points in the Bezier polynomial. Omidi et al. [32] presented a comparison study between trimmed compressor and base one as can be seen in Figure 5. The results showed that the trimmed compressor presented a higher isentropic efficiency compared to the base one, with a maximum difference of $2 \%$.

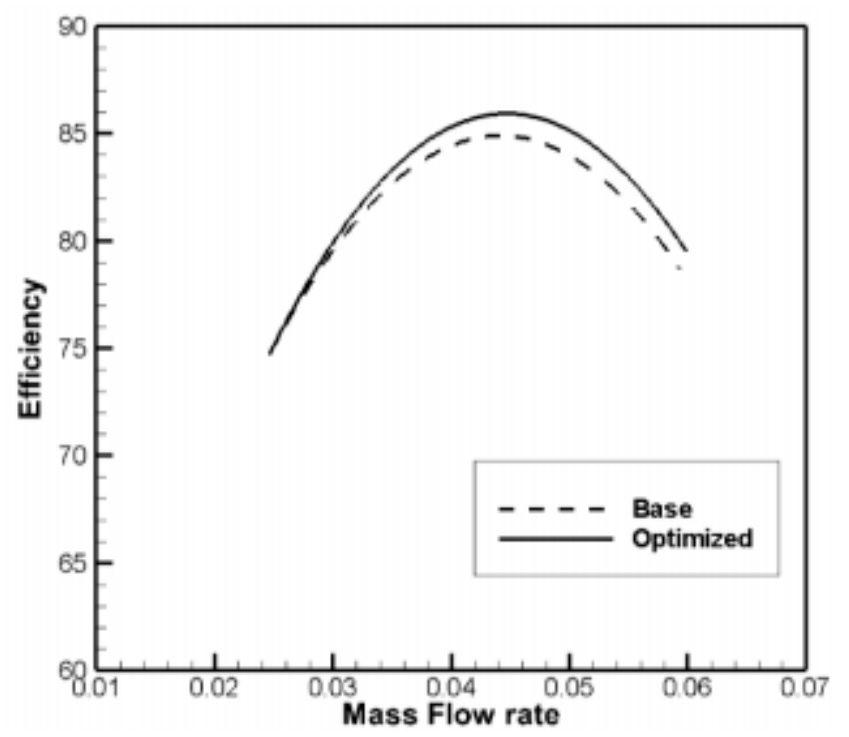

Figure 5. Comparison between trimmed (optimized) and base compressors [32]. 


\subsection{Turbine Technologies}

The aim of turbine is either to generate electricity as in the electrical turbocharging systems or to drive the compressor as in the conventional turbochargers.

\subsubsection{Variable Geometry Turbine (VGT)}

In VGT, Figure 6, the exhaust gas delivered by the engine is controlled and automatically supplied to the turbine in order to permit turbine power to sufficiently provide energy, which drives the compressor at the required boost level wherever the engine is running in its range. This can be accomplished by varying the throat area of the turbine stator in order to control the mass flow of the exhaust gas. As the throat area decreases, the exhaust pressure and the rotational speed increase. Contrarily, increasing the throat area reduces the exhaust pressure and, consequently, the turbocharger boost decreases.

(a)

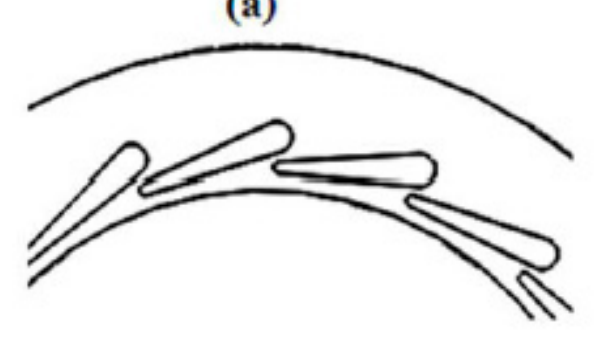

(b)

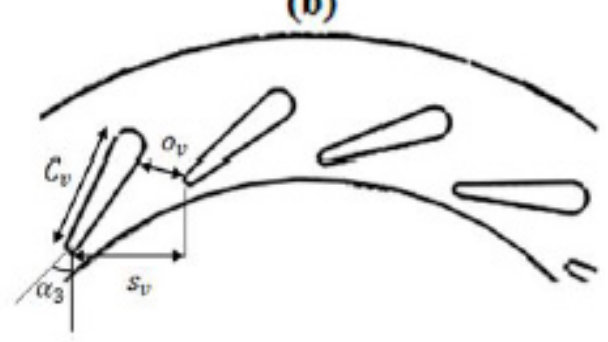

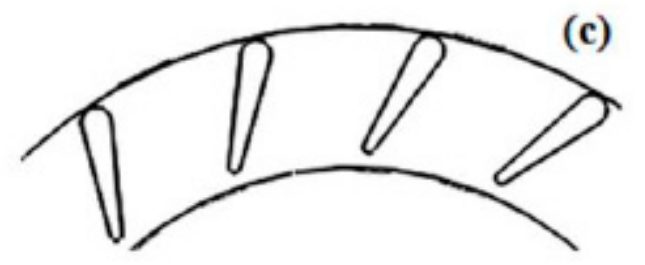

Figure 6. Turbine with different stator positions (variable geometry turbine (VGT)), (a) closed, (b) mid, (c) open [33].

The configuration of the turbine can be axial, radial, or mixed flow. Axial and radial turbines are commonly applied in turbocharging. However, small axial flow turbines suffer from the high tip leakage at the rotor blade. Similarly, radial turbines have a limited operating range because of its inlet geometrical requirements. Mixed flow turbines (which is a modified radial turbine configuration as can be seen in Figure 7) have an advantage of the cone angle, which is between axial and radial. As a result, the design of mixed flow turbines has more freedom and, consequently, a wider range of operation. This enables the mixed flow turbines to accomplish higher mass-induced mass flow rate and optimum efficiency at lower velocity ratios, compared to equivalent radial ones. 


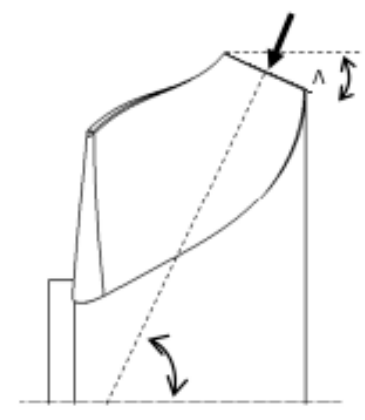

Mixed flow turbine

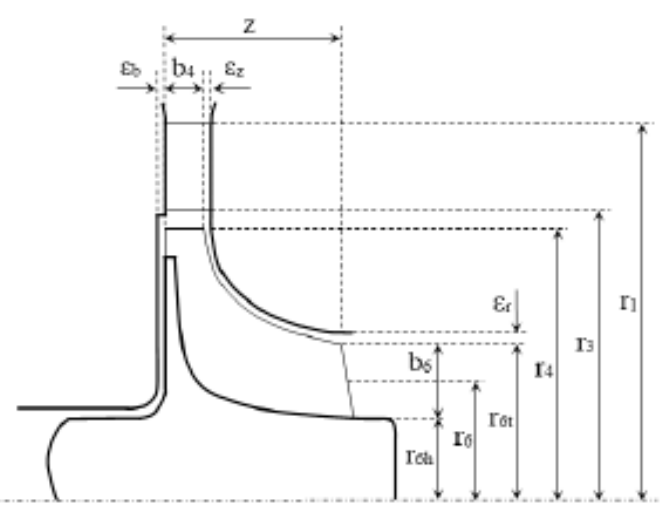

Radial flow turbine

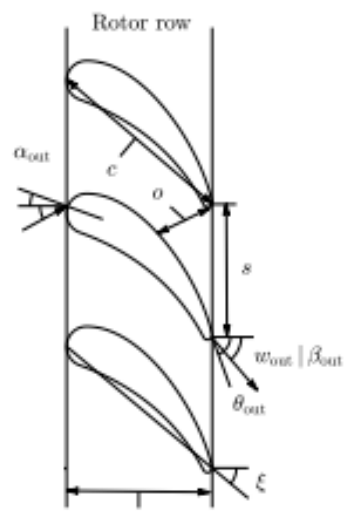

Axial flow turbine

Figure 7. Configuration of mixed flow turbine [34], radial inflow turbine [35] and axial flow turbine [36].

Baets et al. [37] presented a direct comparison between the efficiency fixed and variable geometry mixed flow turbines. As shown in Figure 8, the efficiency curve of the VGT is slightly lower because of sealing losses and the geometry losses in the nozzle ring. However, Ishino and Bessho [38] improved the geometry of the nozzle ring by applying pivoting technique in which the nozzle vanes are pivoted at the trailing edge. Their results showed a 14\% improvement of the pivoted VGT compared to conventional VGT.

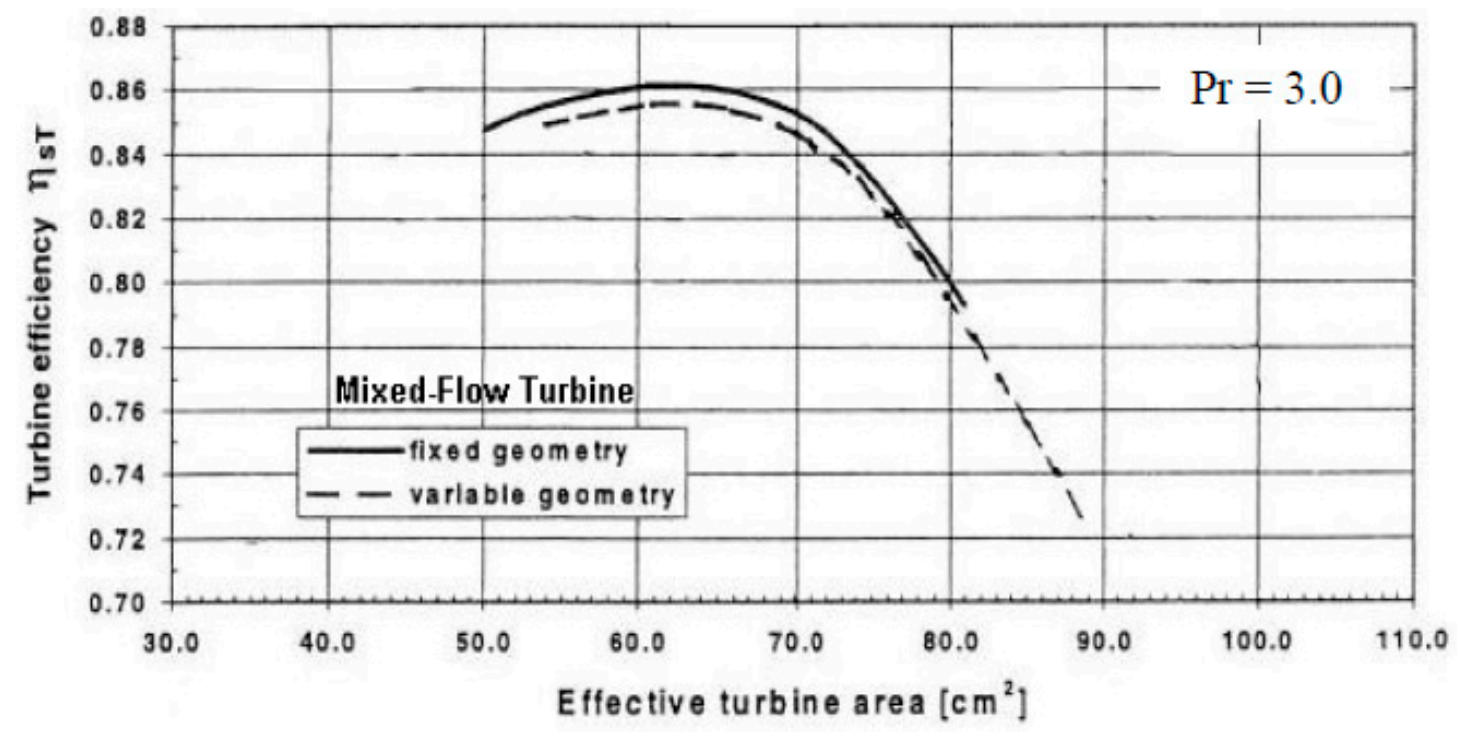

Figure 8. Comparison between fixed geometry and variable geometry mixed flow turbines.

\subsubsection{Active Control Turbocharger}

An interesting development to the VGTs in recent years has been the active control turbocharger (ACT) developed by one of the co-authors and his research group at Imperial College London [39]. This system has a significant theoretical potential and consists of a variable geometry mechanism (both in pivoting vane and sliding wall versions), which is opened and closed at the frequency of incoming pressure pulses at the turbine inlet. It, therefore, required a more robust nozzle and actuation system and a high-power actuator to be able to achieve this type of operation. By optimizing the turbine throat area throughout each exhaust gas pulse, it could recover significantly more energy than a conventional VGT system. However, there are several practical issues with the control and reliability of operation of the mechanism in a real engine environment and it has so far not seen production [40]. 


\subsubsection{Twin and Double Turbine Scrolls}

Figure 9 illustrates the difference between the twin entry and double entry configurations in turbines. Two turbocharger turbine entries are used to ultimately increase the energy of the exhaust driving the turbine in which the turbine wheel is directly fed with the highly pulsating flow twin or double turbine scrolls. The double entry scroll delivers better efficiency at full load while the twin entry scroll presents better performance at partial load.

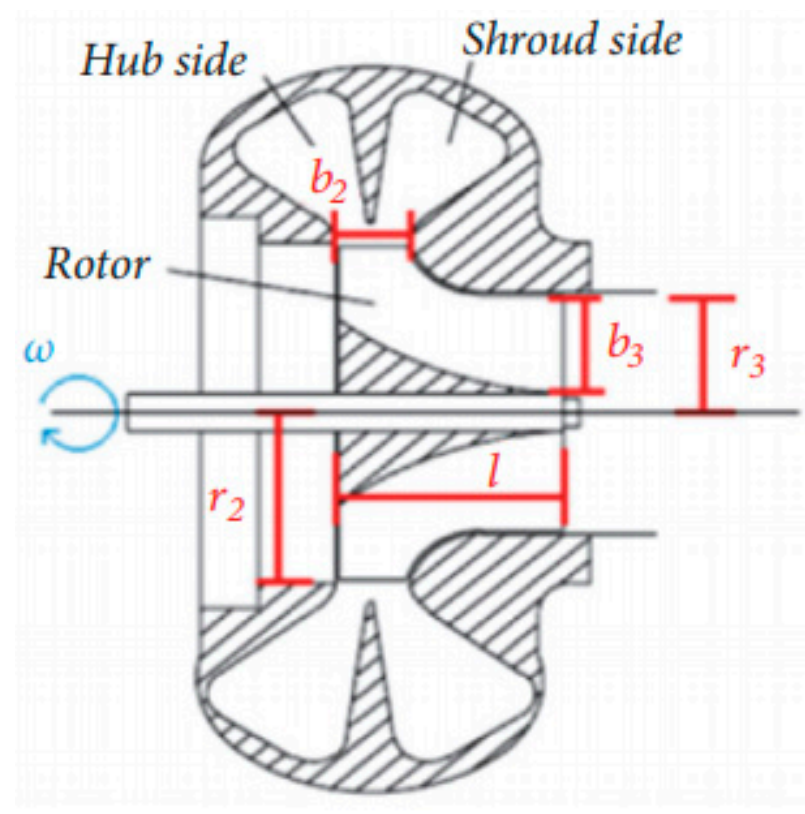

(a)

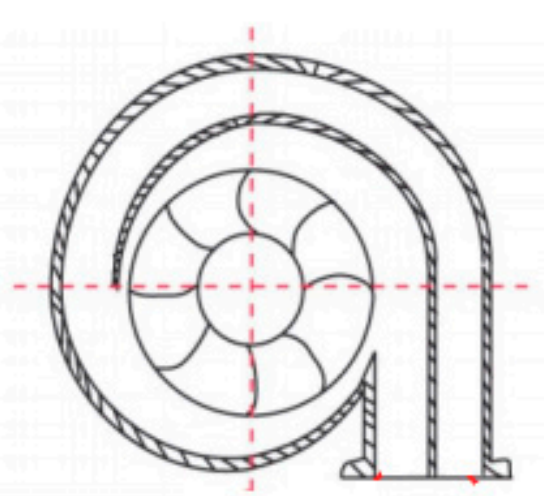

(b)

Figure 9. (a) Twin entry [41]; (b) double entry scrolls turbines.

\section{Supercharging}

According to Watson and Janota [42], 'supercharging can be defined as the introduction of air (or air/fuel mixture) into an engine cylinder at a density greater than the ambience'. This process allows a proportionally huge amount of fuel to be burned, thus increasing the potential power output of the engine. Three basic methods, namely, turbocharging, pressure wave supercharging, and mechanical supercharging, are used to achieve this condition.

\subsection{Turbocharging}

A turbocharger is a device with a compressor and turbine on a single shaft, and the turbine is powered by energy in the engine's exhaust gases to drive the compressor and increase the intake pressure. The design of such turbomachines is widely available in literature such as [43-46].

A Sankey diagram for a typical 1.4 L four-cylinder spark ignition (gasoline) engine is shown in Figure 10. A maximum of one-third of fuel energy is converted into useful work, and an average of $15 \%$ of fuel energy is wasted as exhaust heat. One major benefit of a turbocharger is that it utilizes exhaust gas energy that would otherwise be wasted, thus leading to an overall improvement in thermal efficiency. 


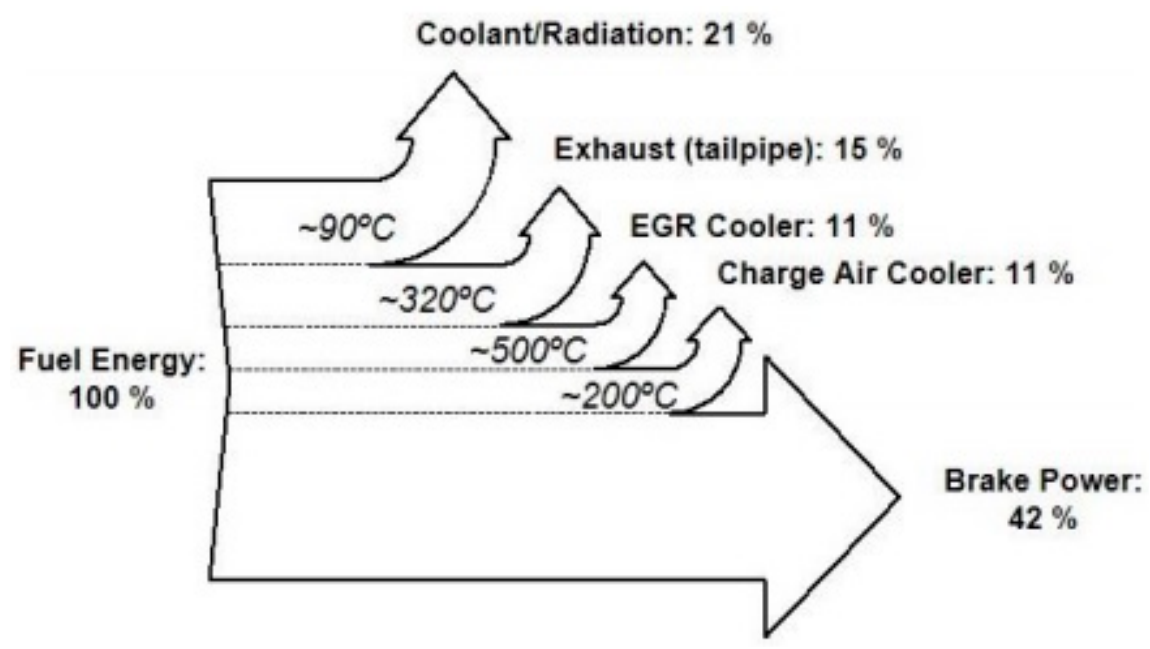

Figure 10. Sankey diagram showing energy balance for naturally aspirated spark ignition engine [47].

In other works (particularly in Watson and Janota [42] and Baines [48]), conventional automotive turbochargers use a centrifugal compressor and radial flow turbine. Such turbomachines have an optimum operating point and 'are unsuitable for operation under various flow ranges' [42] because of their design and operating principles. This case is applicable for an automotive engine. Emission reduction technologies, such as exhaust gas recirculation and diesel particulate filters, render compressor and turbine matching as problematic [49] Several authors [17,42,48,50,51] indicated a fundamental agreement when matching a turbocharger and an engine, that is, torque at low speed and power at high engine speed. A large turbocharger provides power at high speed but experiences low-speed performance and transient response because of the lack of exhaust gas flow rate to overcome the inertia of the system. A small turbocharger provides improved low-speed torque and transient response because of the reduced inertia, although it requires turbine bypassing to prevent excessive turbocharger speed at high engine speeds, thus sacrificing the efficiency. Small turbochargers generally exhibit low efficiency because of the increased leakage pressure losses between the turbine and housing. This low-speed performance impairment is compounded with highly boosted engines $[17,52]$. The drivability characteristics of a comparable naturally aspirated unit are the aim of a forced reduction engine, and various solutions have been introduced to diminish the effects of this turbocharging compromise.

A turbine bypass—or 'wastegate' - actualizes the correct sizing for a turbocharger under low engine speed [48]. The wastegate is opened with an increase in speed, thus allowing a proportion of exhaust gas to bypass the turbine, limiting the boost pressure and preventing the overspeeding of the turbocharger. However, thermal efficiency is relinquished because the bypassed exhaust gas energy is wasted.

Variable geometry turbine indicates that the effective turbine area (or aspect ratio) can be matched to the changing exhaust gas flow rate [53]. The concepts designed to achieve this condition can be classified into two categories depending on the adjustability of the geometry of the volute or nozzle. According to Matsura et al. [54], a turbocharger with variable geometry volute is a low-cost alternative to variable geometry nozzle arrangements, which are generally complex. Despite experimentally demonstrated improvements in transient response [54-56], only a few variable geometry volute designs have attained commercial production. Baines [48] indicated that this condition may be because of the aerodynamic inefficiency issues relative to fixed geometry counterparts and the durability and performance deterioration in service. Turbochargers with variable nozzle geometry have achieved huge commercial success. Variable nozzle devices have two principal types, namely, pivoting vanes and moving sidewall [48], and can provide (amongst other benefits) improved transient performance [54] and low speed boost [57]. By using a variable nozzle turbocharger fitted to $1.8 \mathrm{~L}$ direct injection diesel engine, Hawley et al. [58] increased the torque in the entire engine speed range compared with an 
equivalent fixed geometry unit. Wijetunge et al. [17] and Matsura et al. [54] believed that variable geometry turbochargers rely on the build-up of exhaust gas energy and thus do not completely solve the problem of transient response, particularly at low engine speeds. Variable nozzle devices with huge proliferation (as opposed to variable geometry volute) shall be referred to as 'variable geometry turbocharger' (VGT).

Various arrangements are used in multiple turbochargers and generally classified into three categories, namely; series, parallel, and sequential. Several factors limiting the pressure ratio, such as efficiency reductions at high-pressure ratios, mass flow range requirements, and temperature limits [48], can be overcome by a single compressor. A series turbocharged configuration may become viable with the increasing boost pressure (i.e., pressure ratio) requirements, which is the case in downsizing. Considering a two-stage system, two turbochargers are placed in series such that the exhaust gases undergo two expansion stages and the intake charge goes through two compression stages. Watson and Janota [42] indicated that 'high overall pressure and expansion ratios may be developed by using conventional turbochargers' without relinquishing efficiency or mass flow range. Series systems may include bypass valves (for turbines and/or compressors) for immense operation flexibility as shown in Figure 11 (reproduced from Pflüger [59]). A two-stage arrangement by Pfluger [59] on a $12 \mathrm{~L}$ commercial diesel engine showed increased torque at all engine speeds, increased rated power, improved air supply, reduced BSFC and smoke, and potential to reduce NOx emissions compared with an equivalent single-stage system. Although transient tests are not performed, the transient response could potentially be improved with a two-stage system. Baines [48] and Watson and Janota [42] highlighted the disadvantages of series turbocharging, such as the costs of extra turbocharger and intercooler (which is usually required), increased bulk and complexity of the system, and additional pressure losses. Baines [48] stated that the transient performance of a two-stage system is generally worse than that of an equivalent single-stage unit because the exhaust gas energy available to accelerate the two turbochargers is shared between them. In a computational investigation by Saulnier and Guilain [60], a 2.0 L diesel engine was downsized to $1.5 \mathrm{~L}$ by moving from single-stage to two-stage turbocharging; equivalent steady-state performance was easily achieved, but the low-speed transient response worsened. 


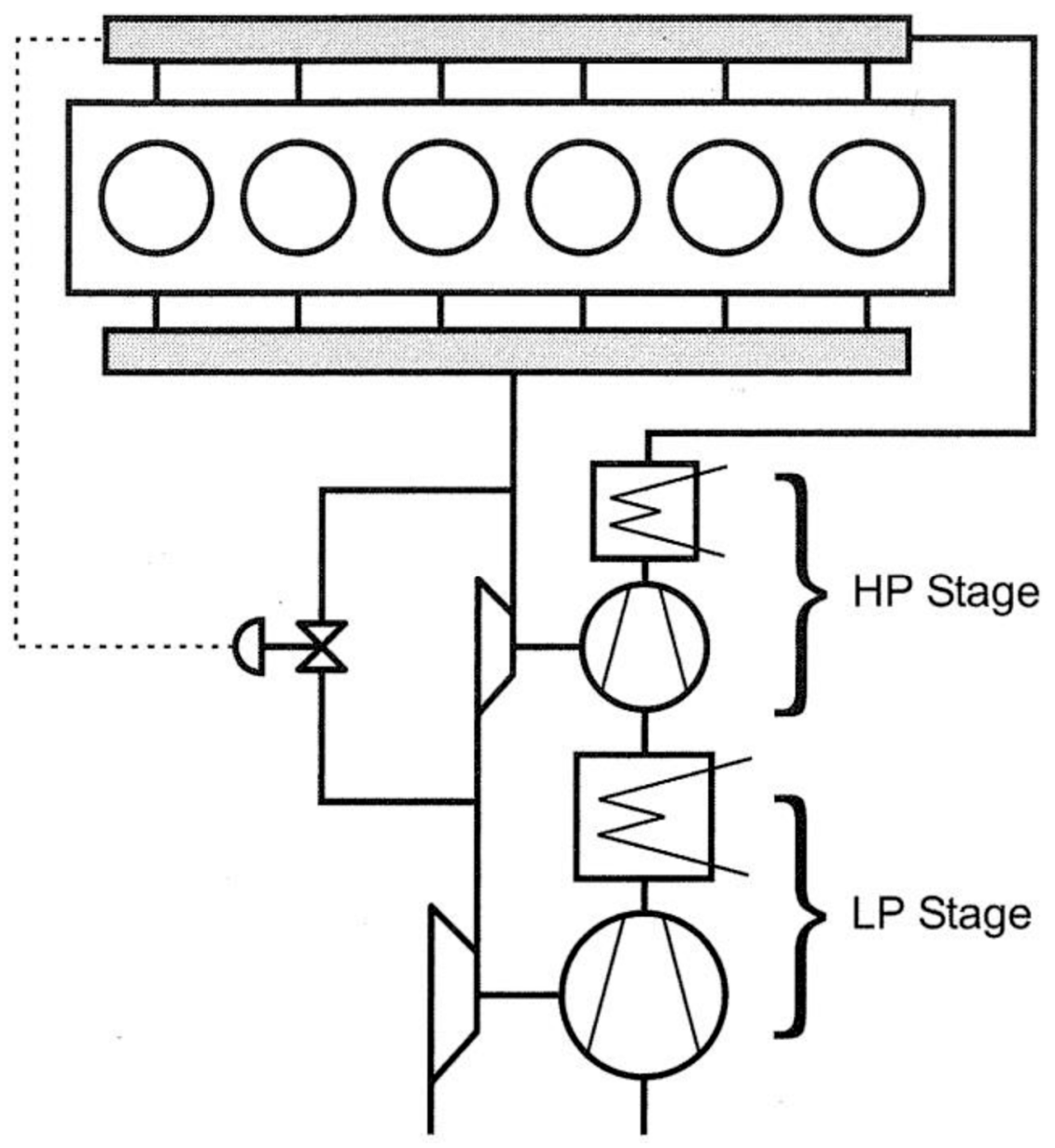

Figure 11. Schematic diagram of regulated series (two-stage) turbocharging system [59].

In a parallel turbocharged arrangement, two (or four) turbochargers of equal size are used to replace a large single unit. Parallel turbocharging is typically used on engines with six or more cylinders by dividing the exhaust pipes from the cylinders into groups, which are favourable for exhaust pulse effects (pulse turbocharging is comprehensively studied by Watson and Janota [42]). In a system with two turbochargers, each turbine receives exhaust gases from half of the cylinders of the engine, and the compressors generally feed into a common intake plenum on the intake side as shown in Figure 12. For the aforementioned exhaust pulse effects, the benefits of parallel turbocharging are reduced (combined) turbocharger inertia for improved transient response [61,62] and simplified packaging, particularly for V-type engines [42,61]. As discovered by Sommerhoff [61], the net gain of a parallel system is controversial compared with that of a single turbocharger setup because of some factors, such as the high efficiency of large turbomachinery and an associated reduction in back pressure. 


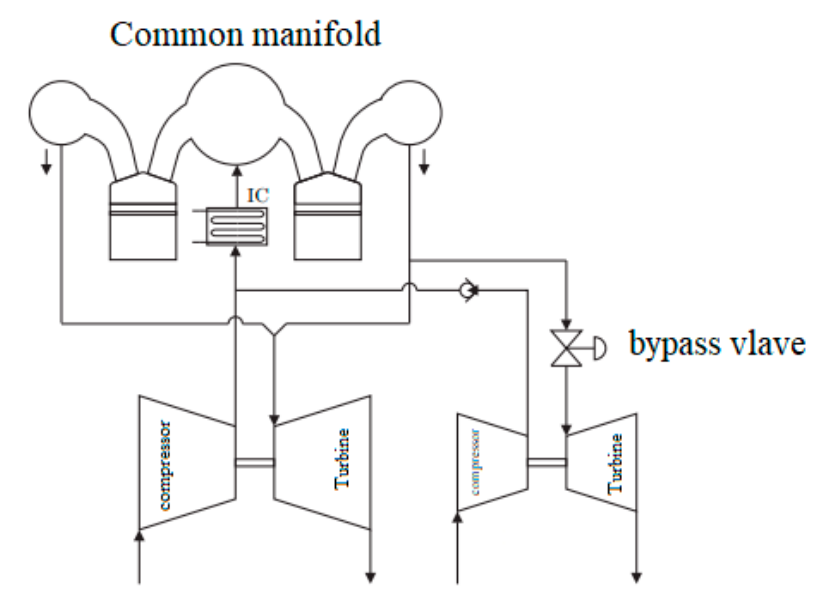

Figure 12. Schematic diagram of a parallel twin turbocharging system.

In a sequential system, Figure 13, two (or more) turbochargers are arranged in parallel and supply charge air to a common intake manifold, similar to parallel turbocharging. Different from a purely parallel configuration, the turbines are driven by exhaust gases from a common exhaust manifold, and the number of turbochargers in operation varies depending on the systematic use of flow control valves. The turbochargers used may be of equal (or similar) size. For a twin-turbo system, only one turbocharger is in operation during the first sequence (at low engine speeds), and two turbochargers are used during the second sequence (high engine speeds). Tashima et al. [63] developed this system for a 1.3 L gasoline rotary (Wankel) engine. Alternatively, a small turbocharger may be used for low engine speed operation, switching solely to a large turbocharger at high engine speeds. Hancock et al. [15] used this system but serially arranged the turbochargers on a highly downsized 1.2 L three-cylinder GDI engine. These two cases have a similar purpose and result: Changing the effective turbine area to match the engine speed and exhaust gas flow and improve the low-speed boost, torque, and transient response. Baines [48] described the effect to 'a stepwise variable geometry scheme'. In the aforementioned work of Tashima et al. [63], boost pressure and torque were substantially improved (by $200 \%$ and $36 \%$, respectively) at low engine speeds compared with those of a conventional turbocharger. In vehicle acceleration tests, transient response was markedly superior as indicated by the $43 \%$ reduction in the time taken to reach maximum boost. Similar improvements were exhibited in computational simulations of a $2.5 \mathrm{~L}$ four-cylinder gasoline engine conducted by Brüstle et al. [64]. For the disadvantages of sequential turbocharging, Tashima et al. [63] and Baines [48] indicated the need for systematic matching of the turbochargers and engine speed with sequence transition, which is crucial in avoiding a drop in torque prior to the switch and compressor surge (and choking). For other multiturbocharger schemes, additional plumbing and associated potential pressure losses must be considered. In relation to VGTs, Wijetunge et al. [17] asserted that the transient response of any of these turbocharged systems is ultimately limited by the available exhaust gas energy, and any transient response issues are multiplied in highly boosted (e.g., highly downsized) applications. 


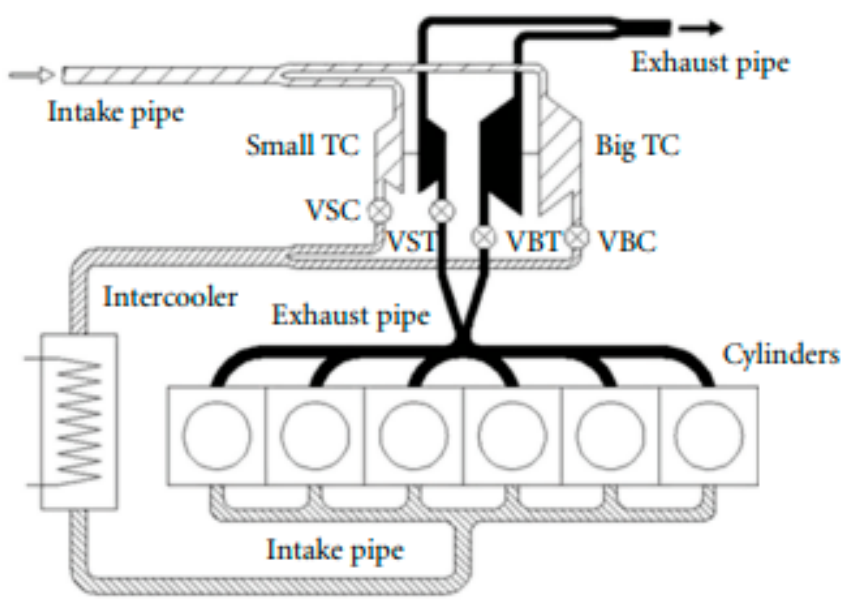

Figure 13. Schematic diagram of a sequential twin turbocharging system [65].

\subsection{Mechanical Supercharging}

Mechanical supercharging occurs when the increased charge air density is provided by a pump or compressor, which is usually driven from the engine crankshaft via a gear train or belt and pulley system. The term 'supercharger' is usually reserved for mechanically driven systems [66], and this precedent will be maintained from here onwards. Superchargers can be categorised based on the compression methods, such as positive displacement and dynamic compressor.

A positive displacement pump displaces fluid in a pipe system by cyclically trapping and discharging a fixed amount of fluid. In an automotive context, increased charge density is accomplished by pumping the air into the intake at a faster rate than the engine would normally ingest. Considering that the rate is fixed relative to engine speed (with fixed drive ratio), positive displacement superchargers are capable of producing a constant boost pressure. The mechanical drive results in good transient response, but the downside is that power is drawn from the useful output of the engine rather than utilising the 'free' exhaust gas energy similar to that in turbocharging. Some of the energy used by the supercharger are recovered as positive pumping work on the pistons [66]; by contrast, a turbocharger raises exhaust backpressure and thus increases pumping losses and trapped residuals [67]. Bhinder [66] indicated that a major disadvantage of positive displacement superchargers is that their size and weight are relative to the boost provided. Many different designs of positive displacement superchargers, including roots, screw (such as Lysholm compressor), sliding vane, and scroll, have been developed and received varying degrees of commercial success. Root-type superchargers do not provide internal compression compared with other types listed here and thus have a relatively low efficiency (Stone [68] for details). Recent developments, such as in Eaton's twin vortices series (TVS) [69], with reduced clearances and improved flow characteristics, have brought a huge improvement. Devices with internal compression, such as Lysholm compressor, provide large volumetric and isentropic efficiencies [70] but require a high cost for manufacturing precision requirements [66]. The analysis of Stone [68] revealed that these efficiency improvements are rapidly eroded when the internal compression ratio of the device does not match the overall required pressure ratio, that is, during external compression (or expansion). A Root-type supercharger was used by Joyce [71] on a $4.0 \mathrm{~L}$ six-cylinder gasoline engine to increase torque and power by $35-50 \%$ and exceeded the output of a naturally aspirated $6.0 \mathrm{~L}$ V12. At part load (equal torque), the supercharged engine has greater BSFC than the naturally aspirated unit because of parasitic losses and reduced compression ratio. However, BSFC is substantially lower for the supercharged engine than the large-capacity V12 under the same conditions due to the increased number of valves (cylinders) and hence higher fuel consumption. Transient performance was not tested against naturally aspirated engines but was expected to slightly diminish. Joyce [71] explained that 'there is a finite time taken to compress the air in the volume between the blower and the engine. Thus, the mass of air delivered by the supercharger is different from that received by the engine' 
under changing speed. Engine performance is reduced in reference to the steady state maximum. This condition formed the basis of using a variable supercharger drive ratio, such as in a CVT. Stone [72] addressed the point of a continuously variable drive ratio but in relation to reducing the part-load throttling losses. Considering the performance differences between supercharging and turbocharging, Richter and Hemmerlein [73] performed a comparative study on a $2.5 \mathrm{~L}$ four-cylinder gasoline engine. The supercharged version showed a torque advantage of $50-70 \%$ at low to medium engine speeds, and torque was approximately identical at high engine speeds. However, turbochargers allow smaller engine displacements to produce much more power relative to their size and improve fuel economy. Joyce [71] and Richter and Hemmerlein [73] applied a bypass valve around the respective superchargers for part-load operation.

Dynamic compressors include centrifugal (radial flow) and axial compressors, and the centrifugal type is more common of the two for automotive supercharger use. A centrifugal compressor works by accelerating the intake air to a high velocity, and this velocity is converted to pressure by means of diffusion [42]. Consequently, the produced pressure ratio increases with the compressor speed. Thus, the mechanically driven centrifugal supercharger boost increases with engine speed at a fixed ratio as reported by Bhinder [66], making it incompatible for automotive engines. This characteristic of centrifugal compressors is not a problem when it is used in a turbocharger because the latter's speed independently varies from engine's speed. Centrifugal superchargers are typically small, light, and capable of producing higher pressure ratios than their positive displacement counterparts. Although the increasing boost with engine speed attribute is a drawback, it also allows the use of a high compression ratio in gasoline engines. In this case, air flow can be improved at high engine speeds where volumetric efficiency would usually drop without significantly increasing cylinder pressures at low to medium engine speeds, thus avoiding auto ignition (knock). This benefit is relevant to applications where performance at high engine speeds is importance, especially on specialist high-performance car manufacturers Koenigsegg and Caterham [58]. Following on from his earlier line of reasoning, Bhinder [66] suggested that driving a centrifugal supercharger through a variable transmission would match the boost to to the engine requirements at any given speed and load. This idea is being developed by Rotrak [67], a joint venture between centrifugal supercharger manufacturer Rotrex and variable transmission specialist Torotrak. The Rotrak device combines a full-toroidal variator with a centrifugal supercharger, where the latter incorporates a compact, innovative epicyclical traction drive patented by Rotrex and has a single-stage step up ratio of approximately 13:1 to achieve the high speeds required by the compressor. No results for performance simulations or engine testing have been published, but the technologies are mature and have been proven individually. Listing the potential benefits of the Rotrak concept for gasoline engines, Stone [67] stated that the engine load via the boost pressure can be controlled (i.e., by controlling compressor speed), thereby reducing the throttling of the engine and the pumping losses.

\subsection{Combined Charging Systems}

At low engine speeds, a pressure charging system would incorporate the transient response and torque, which can be provided by a mechanical supercharger with high efficiency and the part-load flexibility of a turbocharger. One solution to this dilemma is to simply combine a declutchable supercharger with a conventional turbocharger in a sequential series arrangement, and such systems have been investigated, particularly for heavy duty diesel applications [52,54,74]. This configuration shall hereafter be referred to as a 'combined charging system'. Schmitz et al. [52] investigated a combined charging system for a $10.9 \mathrm{~L} \mathrm{V6}$ commercial diesel engine with a positive displacement supercharger (Wankel-type, which has internal compression) that is upstream of a fixed geometry turbocharger. An electromagnetic clutch was fitted to the supercharger drive pulley for the supercharger to disengage (in conjunction with an intake bypass valve) at high engine speeds or low loads and maintain efficiency. Compared with the purely turbocharged engine, the combined charging system provided significantly increased low speed boost and torque with only a small BSFC penalty. Available 
engine braking power was vastly improved. For transient performance, the time taken to reach maximum engine speed from idle was reduced by more than $30 \%$ during the simulations of loaded vehicle acceleration.

Matsura et al. [54] tested a similar system with a Wankel-type supercharger on an $11 \mathrm{~L}$ six-cylinder commercial diesel engine. The base engine was fitted with a VGT, and the supercharger was downstream of the turbocharger and intercooler. Low-speed torque was increased by $50-60 \%$, and loaded vehicle acceleration was reduced remarkably by $65 \%$. Smoke and BSFC could be reduced whilst achieving the same torque curve because of the improved air supply. Tomita et al. [74] investigated a combined charging system similar to the two previous systems on an $8.8 \mathrm{~L}$ six-cylinder heavy duty diesel engine. A Lysholm screw-type supercharger (positive displacement, with internal compression) was fitted downstream of the turbocharger and prior to the intercooler, and the turbocharger featured a wastegate. The addition of the supercharger be substantially increased the low-speed torque whist improving the air-fuel ratio (AFR), thereby reducing the smoke levels. BSFC was comparable for the two systems with some improvement at low engine speed. Approximately $20-55 \%$ of the power used to drive the supercharger was recovered as positive pumping work, and the amount recovered decreased with the increase in engine speed. For transient response, loaded vehicle acceleration tests showed that acceleration times were reduced whilst simultaneously improving the transient boost pressure and AFR.

The idea of the combined charging system has not been explored by the heavy-duty diesel sector. Volkswagen has successfully implemented this technology on a 1.4 L GDI engine [75]. A Root-type supercharger was used in conjunction with a fixed geometry turbocharger. As reported by Whitworth [76] at the time the 'twincharged' engine was released to market, Volkswagen claimed that it 'delivers the equivalent performance of a naturally aspirated $2.3 \mathrm{~L}$ four-cylinder engine, but with a significant drop in fuel consumption', thus costing less than a modern turbocharged HSDI diesel engine and is equally reliable. For passenger car diesel engines, Cantore et al. [77] downsized a $2.5 \mathrm{~L}$ four-cylinder turbocharged HSDI diesel engine to $1.8 \mathrm{~L}$ by adopting a combined charging system from a computer model without reduction in steady state or transient performance. Approximately one-third of the power consumed by the supercharger is recovered as pumping work, and the downsized engine significantly delivers better part-load fuel consumption than the baseline for points along a typical driving cycle. One of the authors of the previous work, Mattarelli [78] conducted a computational study for a $2.8 \mathrm{~L}$ four-cylinder HSDI diesel engine by comparing the performance of a combined charging system with a series sequential turbocharged arrangement and a baseline engine, which is fitted with a VGT. The turbocharger of the combined system was a VGT, which was the high-pressure turbocharger of the sequential system. The two configurations provided increased steady state torque (up to $14 \%$ ) and slightly reduced BSFC over the baseline. In simulated vehicle accelerations from $70 \mathrm{~km} / \mathrm{h}$ to $120 \mathrm{~km} / \mathrm{h}$, the sequential and combined systems were approximately $14 \%$ and $25 \%$ quicker than the baseline, respectively. For reference, a sequential system with fixed geometry for the two turbochargers provides smaller improvement than the baseline single VGT system in a steady state and performed only marginally better than the baseline $(\sim 3 \%)$ in the acceleration test. A positive displacement supercharger was used in each of these examples of combined charging systems.

\subsection{Existing Electric Forced Induction Systems}

In this section, the operations of five different technologies of electric forced induction systems (EFIS) are presented as shown in Figure 14. The five existing technologies of electric turbochargers and superchargers are:

(1) Electrically assisted turbocharger (EAT);

(2) Electric compressor (EC);

(3) Electrically split turbocharger (EST);

(4) Turbocharger with an additional electrically driven compressor-upstream (TEDC); 
(5) Turbocharger with an additional electrically driven compressor-downstream (TEDC) fluids.

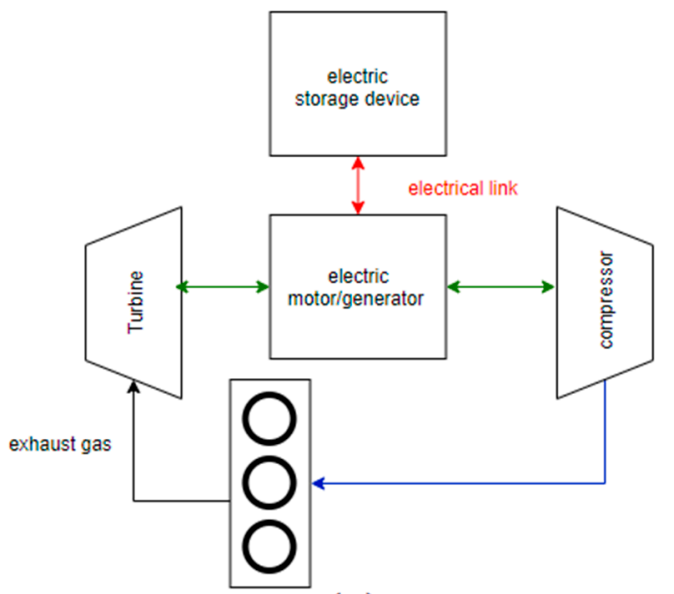

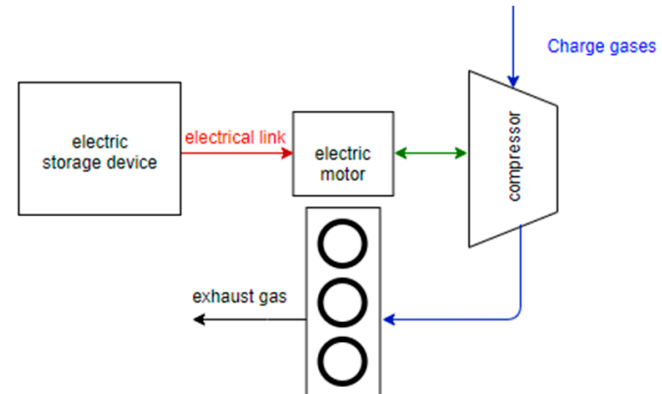

(b)

(a)

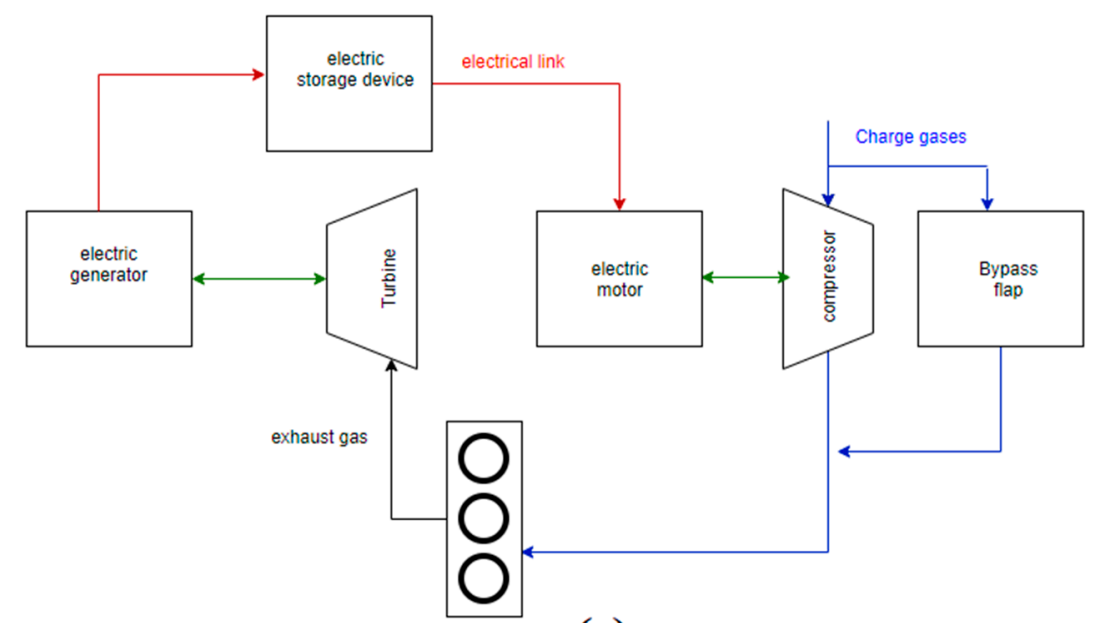

(c)

Figure 14. Cont. 


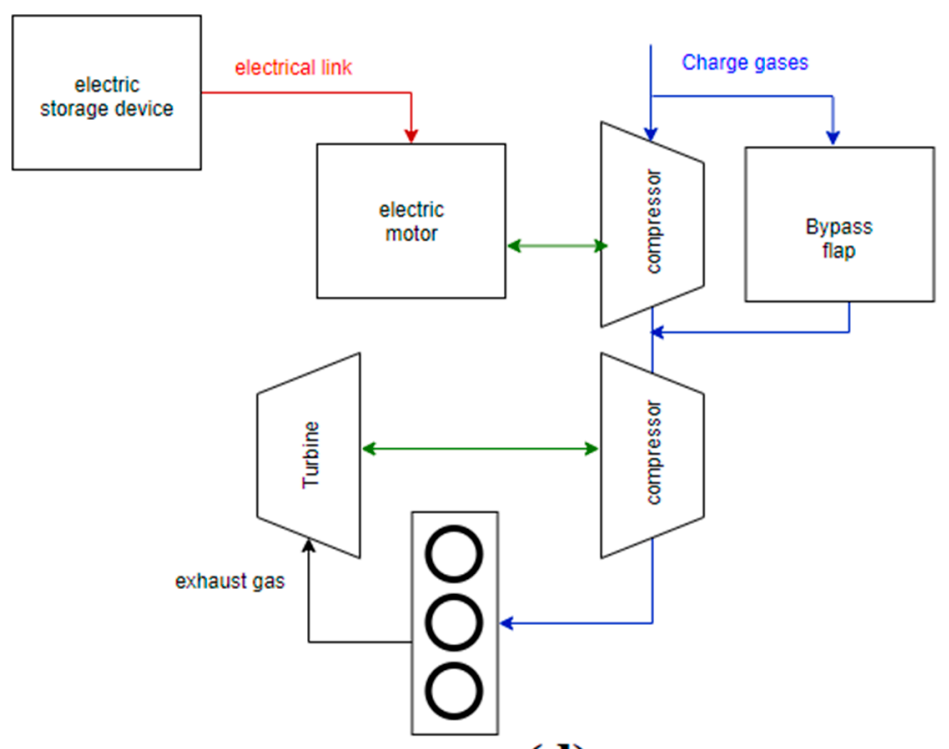

(d)

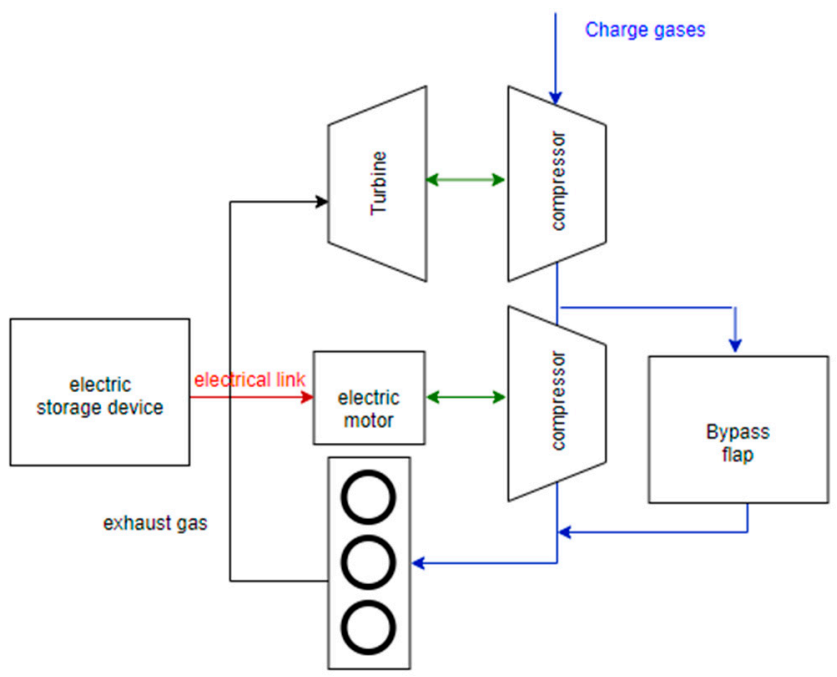

(e)

Figure 14. Schematic layout of electric forced induction system (EFIS) topologies (black line (thin)—power flow, black line (thick) —air flow path with valve, blue line-engine inlet air flow, red line-exhaust gas flow). (a) Electrically assisted turbocharger (EAT). (b) Electric compressor (EC). (c) Electrically split turbocharger (EST). (d) Turbocharger with an additional electrically driven compressor-upstream (TEDC). (e) Turbocharger with an additional electrically driven compressor-downstream (TEDC).

\subsubsection{Electrically assisted turbocharger}

The electrically assisted turbocharger (EAT, also referred as hybrid turbocharger) topology is shown in Figure 14a. Between the compressor and the turbine, a high-speed electric machine is fitted [79], see Figure 15. At low engine speed, additional torque is provided to the compressor, as the electric machine operates as a motor; thus the boost pressure is increased, which results in the reduction of the transient response [80]. On the other hand, at high engine speed, power is generated and transmitted to the energy storage as the electric machine functions as a generator. 


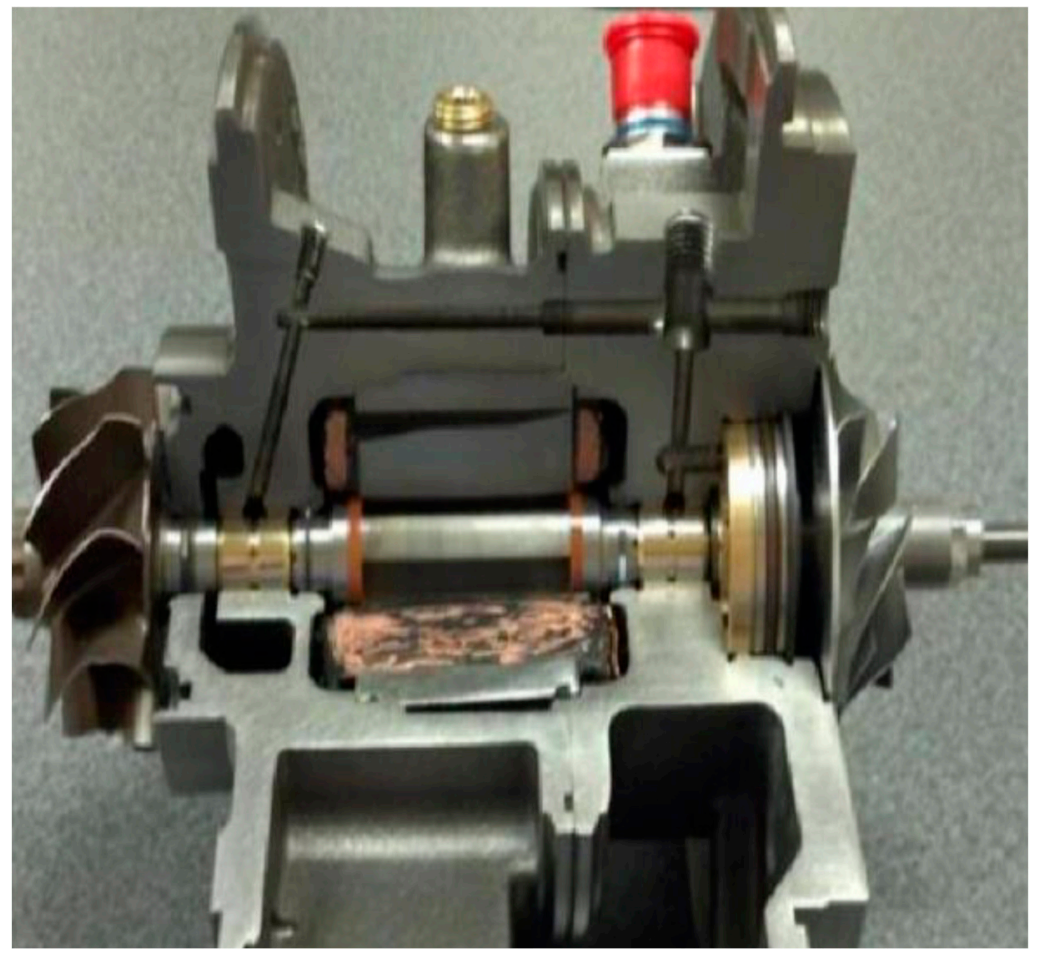

Figure 15. Integration of electric machine with turbocharger.

Ricardo et al. [79] stated that investigation on the electrically assisted turbochargers is needed as they are beneficial to eliminate the turbo-lag. Moreover, another advantage of the hybrid turbochargers is that the turbocharger speed is maintained during gearshifts. In addition to that, at high engine speeds, the turbocharger speed is reduced [79].

Similarly, a recent paper by Lee et al. [81] supported that electrically assisted turbochargers provide higher boosting at low RPM than a conventional turbocharger and the power output, which is consumed by the motor and inverter is low. On the other hand, the shaft inertia is increased since the electric machine is interconnected between the turbine and the compressor [81], thus for the turbocharger operation, more power is required. Furthermore, another drawback of this topology is the high-temperature effect on the electric machine, hence, an additional cooling is needed. To mitigate the high-temperature effect, Lee et al. [81] presented some topological approaches. First, the electric machine can be connected or disconnected to the shaft with the usage of clutches, so the machine can be installed outside of the turbocharger. Second, a large airgap permanent magnet machine could be used, which can be located outside of the turbocharger. This electric machine decreases the temperature effect as the airgap is used as inlet air path.

\subsubsection{Electric Supercharger}

Electric supercharger is also referred as hybrid supercharger or electric compressor or e-booster, see Figure 16. The solely difference between electric supercharger and turbocharger is the omission of the turbine [79] as is shown in Figure 14b. This is beneficial as not only is no additional inertia to the system from the turbine and the turbine shaft, but also because the backpressure effect is eliminated. Similarly, Villegas et al. [82] stated that the friction losses are decreased since there are no mechanical connections between the engine and the e-compressor. Furthermore, in this topology, the boost pressure is increased at the transient response at low engine speeds. 


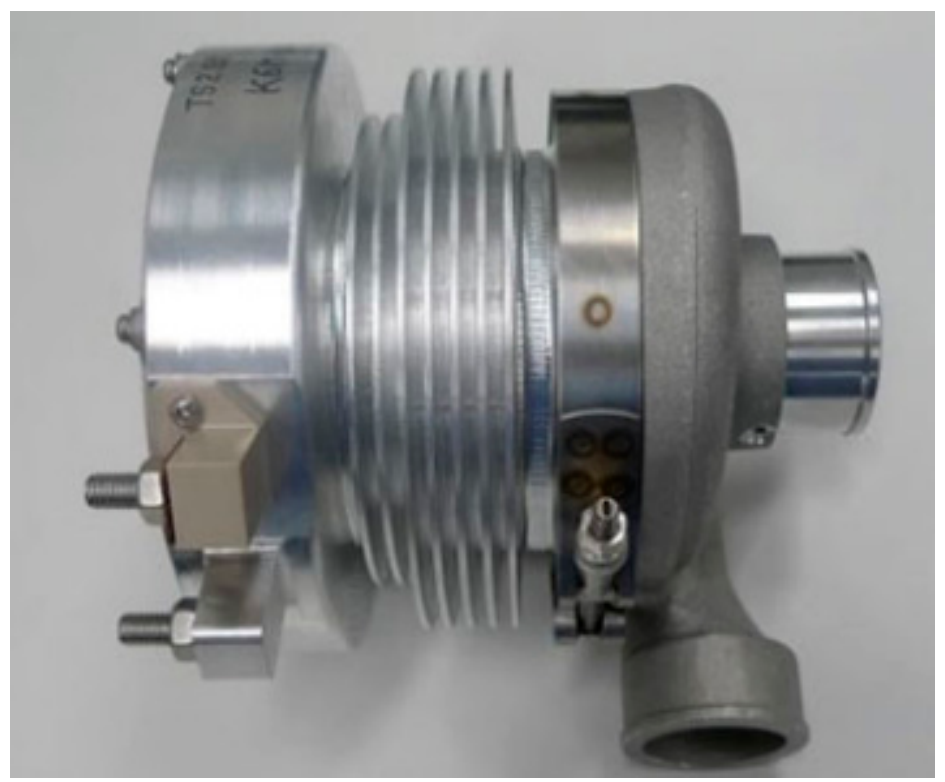

Figure 16. Electric supercharger.

Moreover, the compressor is electrically driven by an electric machine which makes the control more flexible [81]. However, due to the incapability of this topology to generate energy itself, electrical energy has to be provided to the storage by an integrated starter generator (ISG) or the regenerative braking system [83]. In addition, according to Lee et al. [81], the main drawback of this topology is the low system efficiency. Also, the development of the e- compressor has faced a challenge since cars are being designed to work on 12V architecture [84]. However, some automobile makers have been considered to use a $48 \mathrm{~V}$ battery. According to a simulation that was conducted by Nishiwaki et al. [85] for a $48 \mathrm{~V}$ battery system, the regenerative electric power and the motor power were risen as the boosting pressure was increased. This was due to the higher power produced by the $48 \mathrm{~V}$. Consequently, higher boost pressure and fast response time were resulted. Therefore, the electric power that is required for the e-booster operation can be covered by the regenerative energy. Finally, the results of the simulation have shown a significant improvement in the transient response at low engine speeds [85].

\subsubsection{Electrically Split Turbocharger}

As shown in Figure 14c, in the electrically split turbocharger, the turbine and the compressor are not connected to the same shaft. However, the mechanical energy from the exhaust gas is converted to electrical and stored in the energy storage. This energy is used to drive the compressor for boosting [81].

The main advantage of this system is that the compressor and the turbine can rotate independently; hence, they can have different speeds. Moreover, since the compressor and turbine are separated, the temperature effect is decreased compared to an electrically assisted turbocharger [81]. On the other hand, Lee et al. [81] stated that due to the high power output consumption of the motor, generator, and inverters, the system's cost will be increased. Furthermore, there is an additional energy conversion loss as two inverters are required, for the system operation.

\subsubsection{Turbocharger with an Additional Electrically Driven Compressor-Upstream and Downstream (TEDC)}

In Figure $14 \mathrm{~d}$,e, the topology of a turbocharger with an additional electrically driven compressor (TEDC), located upstream and downstream, respectively, is shown. In this turbocharger, the electric machine is connected to the electrically driven compressor and is not affected by the exhaust gas driven turbine. Thus, since the electric machine drives solely the compressor, the transient response is improved for low engine speed as the boost pressure build-up is made faster [83]. Moreover, according 
to Lee et al. [81], the benefits of the topology are the low power consumption of the electric motor and inverter as well as the improvement of the steady state performance. It is obvious that the TEDC downstream has faster transient response compared to the upstream topology since the latter has to compress a larger volume.

In a recent paper by Nishiwaki et al. [85], the topology in Figure 14e is referred to as a two-stage turbocharger system. In addition, in the paper, a TEDC system on a 1.5-litre gasoline engine was examined by GT-Power, an engine simulation tool, and engine bench test. Results obtained by Nishiwaki et al. [85] suggest that the TEDC system's response time at $1500 \mathrm{rpm}$ was improved by $43 \%$, compared with a normal two-stage turbocharger.

On the other hand, the main disadvantage of the TEDC is that the electric energy required to drive the compressor needs to be generated by generator/alternator powered by the engine shaft or regenerative braking system [83]. Furthermore, another major drawback that should be considered is the low system efficiency of the topology [81].

\subsubsection{Superturbocharging}

The combination (electrical or mechanical) of superchargers and turbochargers in a system is referred as Superturbocharging or "Superturbo". Superturbocharging has two principal versions (electrical/mechanical) as follows:

\section{(i) TurboSuperGenerator}

TurboSuperGenerator (TSG), Figure 17, is a super-turbo system that not only benefits from the advantages of supercharging and turbocharging, but also benefits from the multi-stage turbocharging [79]. In the TSG, the engine alternator is replaced as boost is provided by supercharger and turbocharger. Moreover, the difference with the other super-turbo systems is that in TSG topology the turbocharger is placed before the electric supercharger, hence the hybrid supercharger is the highpressure compressor stage [84]. According to Baderman [84], integral Powertrain (IP) has developed a TSG, named SuperGen, which allow an aggressive downsizing without compromising on drivability. Furthermore, IP has proved that the acceleration time of TSG downsized engine was shorter than a normal-sized, naturally aspirated, or a sequentially turbocharged engine [84].

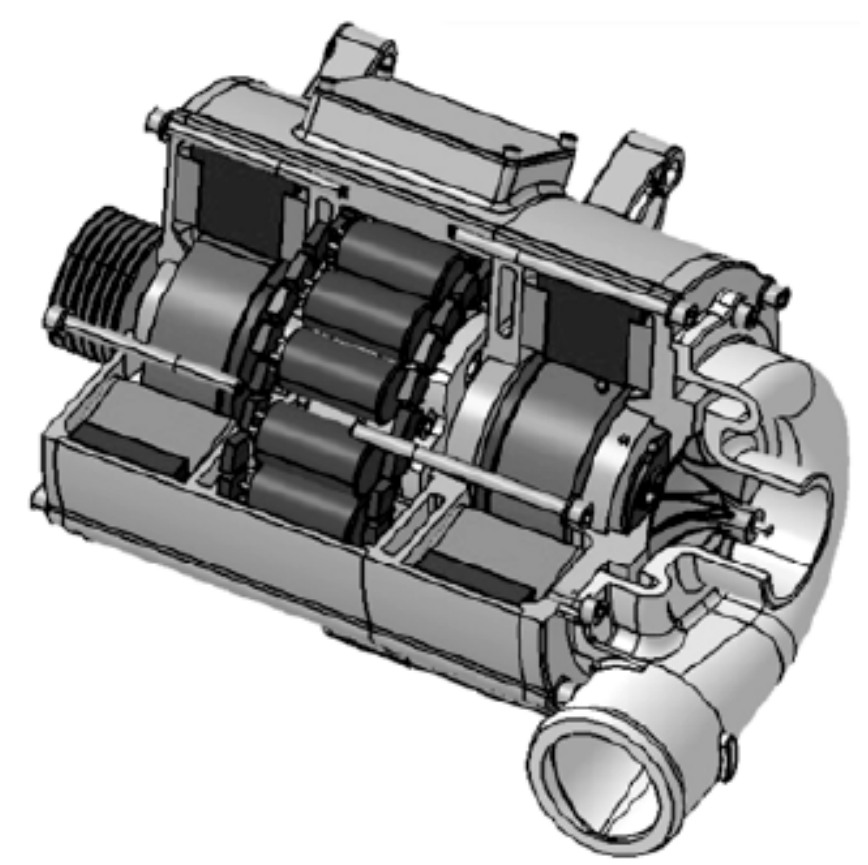

Figure 17. Configuration of Turbosupergenerator (TSG) [79]. 
(ii) Mechanical Superturbocharger

It is an empowering topology for engine downsizing with no loss of vehicle transient response and peak power. As shown in Figure 18, the main elements of the technology are a traction drive, compressor, and turbine all being attached to a single crankshaft and subsequently connected to a continuously variable transmission. This technology consists of two modes. The first one boosts engine power via turbocompounding while the second transmits power from the engine to a supercharger in order to boost the transient response at lower speeds.

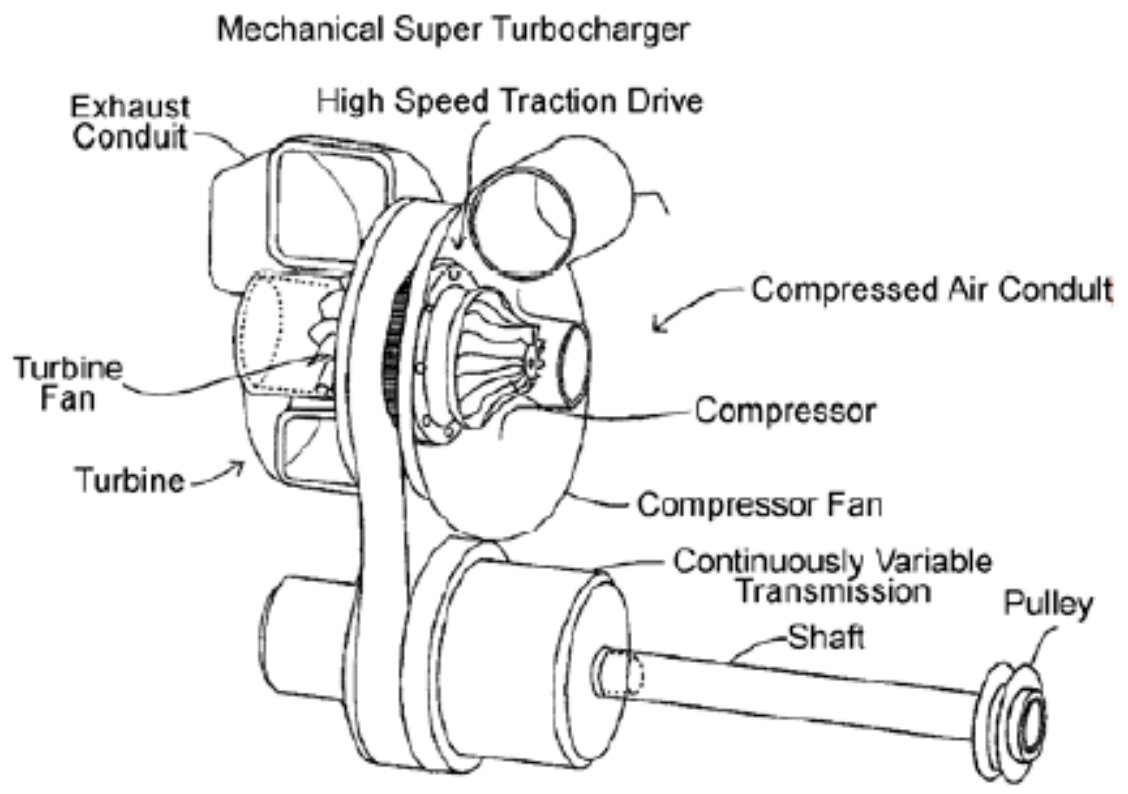

Figure 18. Configuration of Superturbocharger [86].

\section{Turbocompounding}

As discussed in Section 2.1, a turbocharger uses an exhaust-driven turbine to power a compressor and consequently increase the density of the air entering the engine. Harnessing the power produced by the turbine in a different manner, such as by directly adding it to the useful output of the engine, may be a beneficial approach. According to Watson and Janota [42], a turbocompounded engine is one with 'some mechanical linkage and power transmission between the exhaust-gas driven turbine and crankshaft of the engine'. However, this term also describes a system in which the turbine drives an electrical generator, and the exhaust energy is recovered as electrical power. Mechanical and electrical turbocompounding arrangements are explored in the following section.

\subsection{Mechanical Turbocompounding}

Four basic mechanical turbocompounding arrangements with individual particular advantages and disadvantages have been developed (Figure 19, reproduced from Baines [32]). 
(a)

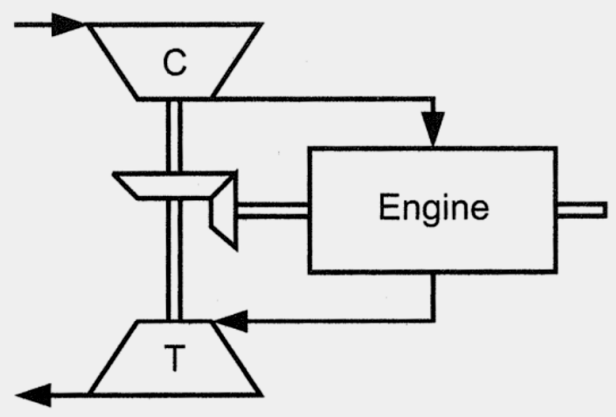

(c)

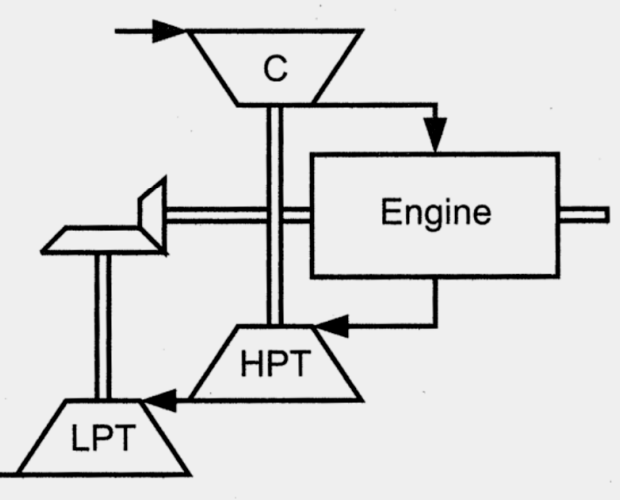

(b)

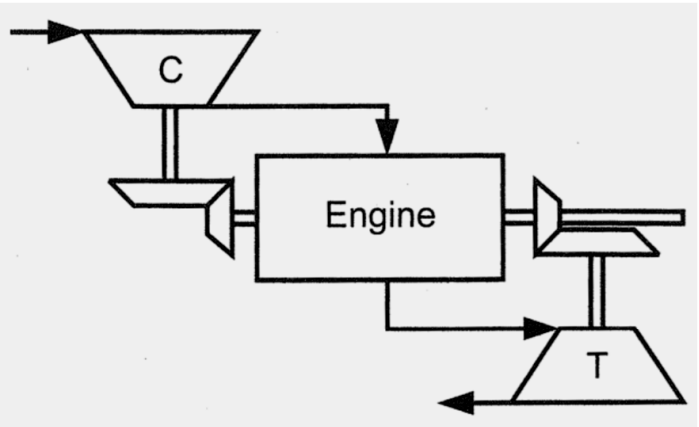

(d)

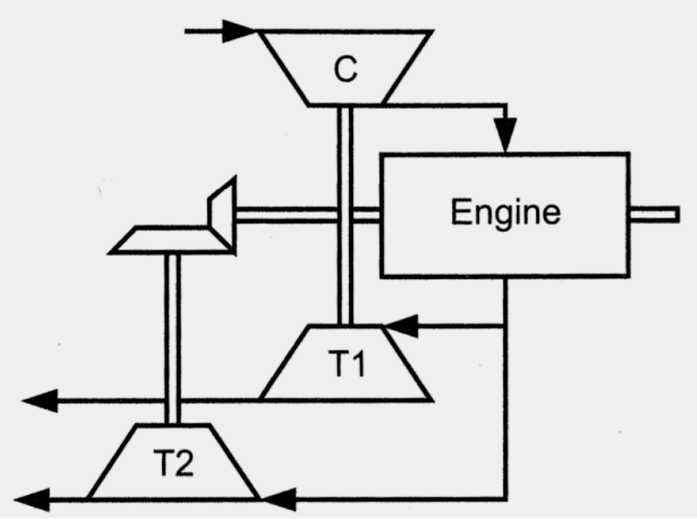

Figure 19. Turbocompounding schemes-(a) directly coupled turbocharger; (b) separately coupled turbocharger; (c) separate power turbine, series arrangement; (d) separate power turbine, parallel arrangement [48].

In the first type, the engine shafts and turbocharger are directly linked (Figure 19a). However, a fixed transmission ratio that corresponds to the engine and turbocharger speeds at all speed and load conditions, with particular problems at part load, is difficult to choose for this arrangement similar to the centrifugal supercharger [42,48]. Brockbank [87] discussed the use of CVT with this arrangement, a modification that independently controls the turbocompounding level of the engine speed. Furthermore, the turbocharger could intentionally be driven by the engine by manipulating the CVT ratio when insufficient boost occurs. Hence, the turbocharger effectively acts as a supercharger. A system of this type (with a CVT) was utilised on the well-known Napier Nomad aircraft engine of the 1950s [42,48]. According to Baines [48], such machine (and other contemporary turbocompounded engines) shows potential but is notoriously complex and quickly superseded by the advancing development of gas turbine engines. Chadwell and Walls [18] investigated the VanDyne SuperTurbocharger, a modern counterpart for the automotive sector that offers supercharging, turbocharging, and turbocompounding in one device. The SuperTurbocharger consists of a turbocharger that transmits power to and from the engine crankshaft via a high-speed traction drive with an integral reduction ratio, a set of reduction gears, a traction drive CVT, and a belt-and-pulley system (Figure 20, reproduced from VanDyne et al. [86]). In the computational study of Chadwell and Walls [18], the SuperTurbocharger was used to downsize a typical 3.2-litre V6 naturally aspirated gasoline engine to a 2-litre four-cylinder unit. The downsized engine produced superior steady state torque but had less satisfactory full-load BSFC. The authors attribute such outcomes to the fuel enrichment and retarded ignition timing necessary to maintain the turbine inlet temperature limit of $950{ }^{\circ} \mathrm{C}$. Nevertheless, part-load fuel efficiency was increased, and a $17 \%$ reduction in fuel consumption over the NEDC was achieved. Simulated transient tip-in tests suggest that the downsized engine has satisfactory transient response; however, it has not been compared with the baseline engine. In this work, a compressor map width enhancement technique was used to facilitate extreme downsizing. Bypassing some of the compressed intake air to the upstream of the turbine's increased mass flow through the compressor at low engine speeds can 
simultaneously prevent surges and generate a high boost. Using the intake air bypass at high engine loads also renders fuel cooling unnecessary. Thus, a torque curve comparable with a 4.2-litre V8 was attained from the 2.0-litre engine and produced better full-load BSFC curve than the previous one. As expected, its part-load fuel economy was also vastly superior with a $36 \%$ improvement over that of the NEDC. During full-load operation, up to $10 \mathrm{~kW}$ of power was transmitted to the device (for supercharging) at low engine speeds, and up to $12 \mathrm{~kW}$ was recovered by turbocompounding at high engine speeds. However, the potential of turbocompounding during part-load conditions was not discussed, and transient performance was not compared.

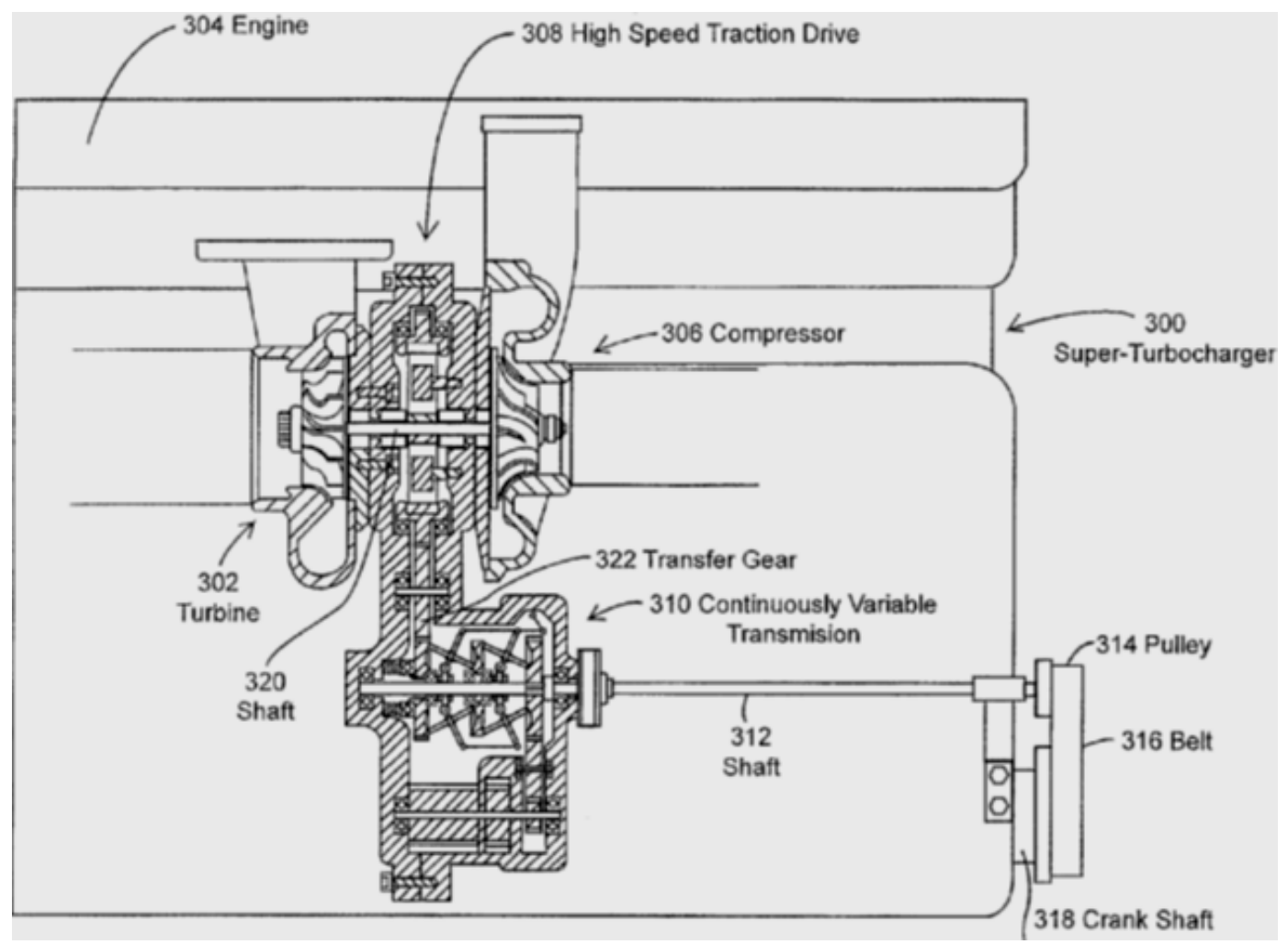

Figure 20. The Van Dyne superturbocharger [86].

It is worth mentioning that in terms of driving cycles, hybrid boosting systems would be favoured if the more relevant and recent WLTP cycle is used. The worldwide harmonized light-duty vehicles test procedure, or WLTP, is a worldwide standard for testing passenger vehicles and light commercial vehicles. As of 1 September 2017, it aims to provide more realistic consumption specifications with its considerably more dynamic testing parameters than previous cycles like NEDC. As a result, the benefit of hybrid boosting is enhanced in WLTP mode, because of the hybrid boosting systems' ability to respond more rapidly and efficiently to the more frequent and more dynamic driver demand changes evident in WLTP, compared to conventional boosting devices and in particular turbochargers.

The second type of mechanical turbocompounding involves a connection of the compressor and turbine to the engine via separate transmissions (Figure 19b). The advantage of this setup is that the compressor and turbine can operate at different speeds, and the turbomachinery can be matched separately. However, the same problems encountered by the previous system will occur unless variable speed drives are employed. A positive displacement compressor (and possibly expander as well) can be used to overcome the low-speed performance deficit, but the problem of part-load operation will persist [42], and the relative inefficiency of such devices renders the potential gains negligible [48]. Wallace [88] developed the concept of a 'differential compound engine' (DCE), in which the compressor is driven by the engine through an epicyclic gear system, and the turbine transmits power to the engine via a fixed speed ratio. This design was initially applied for two-stroke 
diesel engines. Later iterations [89] were adapted for heavy-duty four-stroke engines and used a variable geometry turbine transmitting power through a CVT to ensure optimum turbine efficiency (see Figure 21, reproduced from Wallace et al. [89]). Although the DCE presented numerous benefits over conventional turbocharged diesel engines particularly in terms of steady state and transient performance, fuel economy, and refinement [90], its commercial production has not been attained. Baines [46] reasonably attributed this outcome to the great complexity of the system.

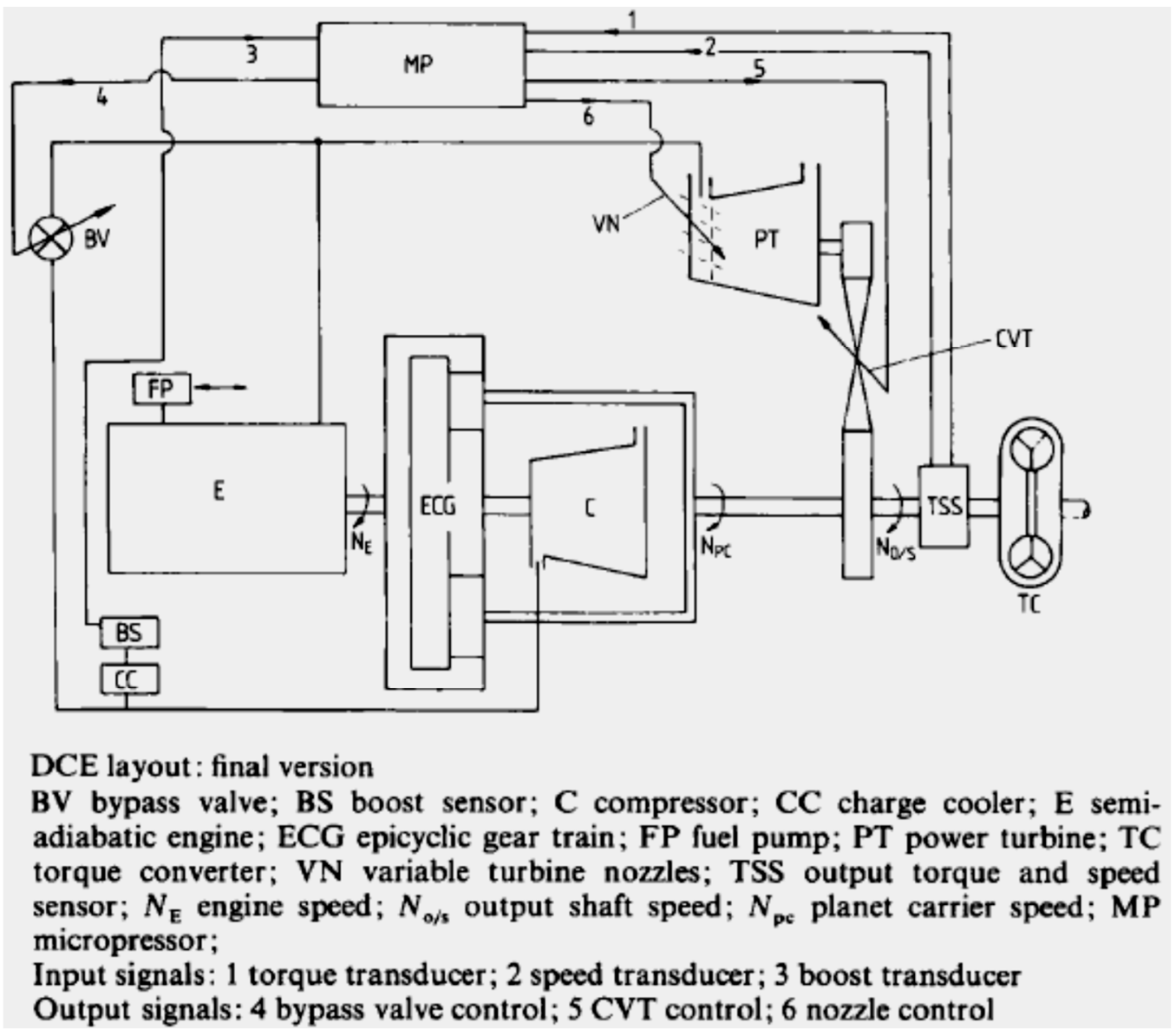

Figure 21. Differential compound engine schematic [89].

The third type of mechanical turbocompounding uses a conventional turbocharger with a second turbine mounted in series with and downstream of the turbocharger turbine. Power from the second turbine-known as a 'power turbine' - is mechanically transmitted to the crankshaft (Figure 19c). Baines [48] and Patterson et al. [91] claimed that this approach is the most common form of turbocompounding and is the first to be commercially used for the heavy-duty vehicle sector by Scania and the turbocharger manufacturer Cummins Turbo Technologies (formerly Holset) [92]. Baines [48] indicated that 'the power turbine, because it is dealing with a gas of lower density, can be larger and rotate more slowly than the turbocharger, and this eases the transmission problem'. However, Watson, and Janota [42] posited that the additional turbine in the exhaust stream increases backpressure due to the increase in the outlet pressure (and thus reducing power) of the turbocharger and the large engine pumping losses. These effects partly offset the benefit of turbocompounding in relation to overall engine efficiency. Nevertheless, Walsham [93] tested and compared various turbocharging technologies and argued that the modified exhaust flow characteristics are caused by the power turbine result in the turbocharger, which behaves similarly to a small turbine at low engine speeds (i.e., with low mass flows) and to a large turbine at high engine speeds. This condition increases boost and transient torque over a conventionally turbocharged engine and improves the 
full-load BSFC. By contrast, the transient response does not match that of a comparable VGT system. The effective turbine area of the VGT can be actively controlled, and the apparent turbine size of the turbocharger in a turbocompounded system is a passive effect that is dependent on engine speed and load. Nevertheless, the turbocompounded system remains superior in terms of BSFC. Wallace [94] conducted a computational study to ascertain the ultimate performance potential of turbocompounded heavy-duty diesel engines by comparing single- and two-stage turbocharging systems with and without additional power turbine for a nominal 8-litre six-cylinder diesel engine. Similar limiting torque curves were achieved with and without turbocompounding for both systems. The two-stage systems have higher BMEP levels that correspond to the greater boost compared with the single-stage system. Conversely, the single-stage systems have similar full-load BSFC values. The greatest efficiency of the turbocompounded engine is skewed towards high engine speeds, in which the power turbine maximally recovers energy. At low loads, the turbocompounded engine loses in relation to efficiency. Under these conditions, the engine must drive the power turbine at a loss because recoverable exhaust energy is minimal, and pumping losses are high due to the increased backpressure caused by the power turbine. For the two-stage systems, the turbocompounded engine has a favourable full-load BSFC curve, but the optimal values are even more skewed towards high engine speeds than those with the single-stage system. The non-turbocompounded engine has the advantage in terms of part-load BSFC for the same reasons stated above. Wallace [94] concluded that turbocompounding 'becomes technically and economically viable only in units operating at very high levels of boost and BMEP'. This conclusion is affirmed by Baines [48], who asserted that turbocompounding 'is not really suitable for application to passenger car engines, for example, which spend most of their time at part load'.

The fourth type of mechanical turbocompounding has a power turbine that is arranged in parallel with the turbocharger instead of in a series (Figure 19d). Baines [48] argued that this configuration may be preferable for large diesel engines, and the power turbine necessary for an equivalent series system would be prohibitively large and expensive.

\subsection{Electrical Turbocompounding}

The various arrangements of electrical turbocompounding systems essentially reflect the four types detailed under Section 3.1. Hence, the first type is fundamentally similar to the electrically assisted turbocharger (EAT), which is described in the section on electrical pressure charging systems. With an appropriate control scheme, the integrated motor of an EAT can function as a generator to recover exhaust gas energy as electrical power. Panting et al. [95] stated that this approach eliminates the need for a wastegate because the turbocharger speed can be controlled by adjusting the power generation level. This observation was corroborated by Katrašnik et al. [96]. Hopmann and Algrain [97] developed an EAT of this type and focused on maximising the fuel efficiency of a 14.6-litre six-cylinder heavy-duty diesel engine. Modifications to the turbocharger included the redesign of the bearing housing and turbine housing interface to insulate the shaft-mounted motor from extreme thermal gradients. A second motor-generator was mounted on the engine crankshaft to provide a two-way energy transfer between the EAT and the engine. Engine performance was simulated for several steady state operating points. The overall efficiency of the electrical system was estimated as $85 \%$ for the simulation. Fuel consumption reduction of $2.5 \%$ to $10 \%$ was predicted with the maximum potential benefit at rated power (i.e., high speed and load). The authors also claimed that this device offers more efficient and flexible operation compared with fixed ratio mechanical turbocompounding systems. Millo et al. [98] investigated the possibility of replacing a VGT with an EAT with turbocompounding capability for an 8-litre six-cylinder diesel engine for urban bus application. They identified the driving cycle of the application as a critical factor of the potential benefit of turbocompounding systems, namely, the proportion of time during which energy can be recovered. This feature was especially pertinent for the currently investigated system because recovered energy is stored in supercapacitors, which could hold sufficient energy for up to six assisted accelerations only. However, the supercapacitors could also be charged from and discharged to the $24 \mathrm{~V}$ vehicle electrical system. Thus, the potential 
efficiency of this system is manifested through the reduced alternator load. Several driving cycles were simulated, and the fuel consumption for the EAT system was maximally reduced at approximately $6 \%$ during free-flowing highway (extra-urban) driving conditions. Nevertheless, the efficiency benefit decreased to approximately $1 \%$ when the proportion of congested traffic conditions increased due to the increasing power requirement for accelerating the EAT and the few opportunities for energy recovery. Predicted improvements in transient response were highly substantial. The EAT achieved the boost target 30\% faster than the VGT during simulated tip-in tests. Hountalas et al. [99] conducted a computational study comparing a mechanical turbocompounding system (with a series power turbine) and an EAT with turbocompounding capability for a nominal 10.3-litre six-cylinder heavy-duty diesel engine. Both systems reduced the primary engine output because of the increased exhaust backpressure and pumping losses. Both also generated a net increase in output because the recovered power through turbocompounding was greater than these reductions. This outcome is consistent with previously findings. With an assumed power turbine efficiency of $80 \%$, the mechanical system provided a maximum BSFC reduction of $4.5 \%$ at full load. The corresponding value for the electrical system was $2 \%$. These values decreased to $0.5 \%$ and $0.2 \%$ at a $25 \%$ engine load. The use of high-efficiency turbomachinery greatly affected the recovery potential of the EAT and increased the BSFC reductions to $6.5 \%$ at full load and $3.3 \%$ at part load. The considerable sensitivity of turbocompounding effectiveness to EAT turbine efficiency was also explored by Millo et al. [98].

The second type of electrical turbocompounding system comprises an electrically driven compressor (EDC) as described under Section 3.4.2 on electrical pressure charging systems with an exhaust gas turbine driving a separate electrical generator. This characteristic facilitates the independent control of the speeds of the separate turbomachines. Each machine can be optimally matched to engine speed and load. Aeristech [100] developed an example of this concept, but performance testing results are currently lacking.

The third type of electrical turbocompounding is similar to the series power turbine system detailed under Section 3.1, but the power turbine drives an electrical generator instead of mechanically transmitting the power to the crankshaft. Patterson et al. [91] performed computer simulations to compare this system with an equivalent mechanical power turbine system for a typical heavy-duty diesel engine. The energy recovered by the electrical power turbine could either directly power a flywheel-mounted motor or be stored in the vehicle electrical system. The authors acknowledged the trade-off between the work implemented by the power turbine and the increase in exhaust backpressure. Such trade-off is unfavourable for the turbocharger and engine efficiencies. They also asserted the need for high turbomachinery efficiency to maximise the benefits of turbocompounding. Simulation results reveal that that both turbocompounding systems improve fuel efficiency, but the electrical power turbine offers greater fuel efficiency benefits at all load points (particularly at part load) where the speed of the mechanical power turbine is constrained by its fixed transmission ratio. Different from the mechanical unit in Section 3.1 with reference to Wallace et al. [94], the electrical power turbine will consume no power at low loads and idle engine.

The fourth type of electrical turbocompounding is the equivalent of the parallel power turbine arrangement listed under Section 3.1, but the power turbine drives an electrical generator. Different from its mechanical system counterpart, the electrical power turbine does not require constant operation [101]. Odaka et al. [102] employed this functionality by using the exhaust gases from the turbocharger wastegate valve to drive the power turbine. The base performance of the engine was unaffected, the exhaust backpressure was not increased, and the exhaust energy that would otherwise be wasted was recovered instead. The parallel power turbine was evaluated on an 8-litre six-cylinder commercial diesel engine in steady-state and transient conditions. Similar to all the other turbocompounding arrangements reviewed, the greatest benefit was achieved at high load and engine speeds-a region in which a typical vehicle engine seldom operates. Hence, the energy recovered at low speed and load was negligible, and the overall effect on fuel efficiency was not predicted. 


\section{Thermal Efficiency Comparison of the Various Boosting Systems}

The different boosting systems are directly compared with a baseline engine in terms of thermal efficiency as shown in Figure 22. As can be seen in the figure, mechanical super turbo demonstrates the highest thermal efficiency of $30 \%$ followed by the electrical supercharging, which presents $24.45 \%$ thermal efficiency. Series sequential turbocharger, turbo-super generator, electrical turbocompounding, and active control turbocharger offer similar performance of $20 \%$. The figure also confirms a better performance of the VGT over that of fixed geometry turbine.

It is worth mentioning that the comparison shown in Figure 22 is based on estimated and modelling results rather than experimental results [79].

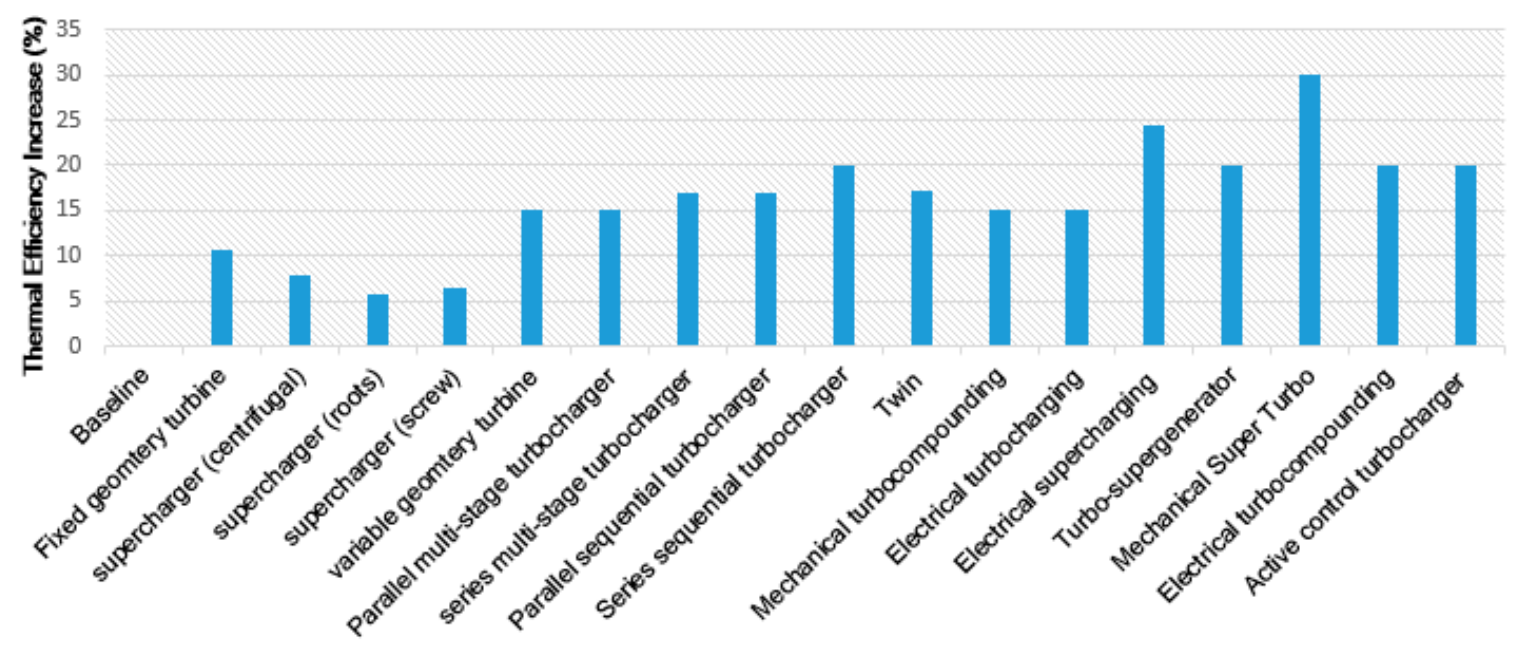

Figure 22. Thermal efficiency of different boosting systems [79].

\section{Conclusions}

Although a variety of boosting methods are available, selection of an optimum method is still difficult since this selection depends largely on the applications. Increased specific power, improved part-load BSFC, and transient performance as close to a naturally aspirated characteristic as possible are the most critical factors for a downsized engine to be effective.

Several turbocharging systems were assessed, including VGTs and different arrangements with multiple turbochargers. Most of these systems showed enhanced specific engine power and fuel efficiency, and faster transient response in comparison with conventional turbocharging. Many authors, nonetheless, insisted that the low-speed torque and transient response of these systems is limited in the long run by the available exhaust gas energy, and these problems worsen in the highly boosted engines $[15,17,54]$. Mechanical supercharging avoids both of the disadvantages, but it is considered with less efficiency than turbocharging because of the parasitic power losses. Supercharging's supporters maintain that, it offers positive pumping work while turbocharging incurs pumping losses because of the exhaust backpressure caused by the turbine-consequently, turbocharging is not free energy recovery [66,67]. However, in turbocharged gasoline engines with variable valve timing system, it is possible to achieve positive pumping at low speed and high loads. Combined charging systems, featuring both a declutchable supercharger and a turbocharger, were found to provide the transient response and low-speed torque of supercharging with the overall efficiency and part-load flexibility of turbocharging. Each of the combined charging systems discussed used a positive displacement supercharger; using a more efficient centrifugal supercharger alternatively may produce additional benefits. Moreover, driving the supercharger through a CVT would provide better flexibility of operation.

Electrical boosting systems-namely electrically driven compressors (EDCs) and electrically assisted turbochargers (EATs) - were also considered. Combined charging systems, which involve 
an electrically driven compressor in place of the mechanical supercharger, have been evaluated by some authors, providing similar performance benefits. It is suggested, nonetheless, that a mechanical arrangement has significant advantages over electrical boosting systems, as the latter are generally limited by problems such as electrical heating and battery depletion or need upgrading of the standard vehicle electrical architecture.

Various turbocompounding arrangements (mechanical and electrical) were discussed. The general agreement of the authors is that it is workable only for high-load operating applications [94], as it offers a small amount of energy recovery at low speed and load. Similarly, Baines [48] declares that turbocompounding 'is not really suitable for application to passenger car engines, for example, which spend most of their time at part load'. Nevertheless, a significant promise has been shown by a particular configuration (the Van Dyne superturbocharger) where the turbocharger shaft and engine crankshaft are mechanically linked via a CVT, and based on the CVT ratio used, provides turbocharging, supercharging, or turbocompounding. Significant levels of downsizing are obviously achievable, whilst attaining the three critical factors mentioned at the beginning of this section.

In conclusion, then, two pressure charging concepts stand out as applicable for providing considerable levels of effective downsizing, and as such are worthwhile of further research:

- A combined charging system consisting of a conventional turbocharger in conjunction with a declutchable supercharger driven through a CVT;

- A turbocharger that is mechanically linked to the engine crankshaft via a CVT, so providing potential for turbocharging, supercharging, and turbocompounding.

Author Contributions: M.A. was the research student that conducted the detailed study and wrote the paper assisted by F.A. who also edited the paper. A.P. conceived of the project, created the layout of the investigations, and checked the analysis and subsequent discussion.

Funding: This research received no external funding.

Conflicts of Interest: The authors declare no conflict of interest.

\section{Notation}

$\begin{array}{ll}\text { DCE } & \text { differential compound engine } \\ S^{-} p & \text { mean piston speed }(\mathrm{m} / \mathrm{s}) \\ \text { EAT } & \text { electrically assisted turbocharger } \\ \text { BMEP } & \text { brake mean effective pressure } \\ \text { TEDC } & \text { Turbocharger with an additional electrically driven compressor } \\ \text { in } & \text { inlet } \\ (F / A) & \text { fuel-air ratio } \\ a & \text { air } \\ A_{p} & \text { total piston area }\left(\mathrm{m}^{2}\right) \\ \rho & \text { density }\left(\mathrm{kg} / \mathrm{m}^{3}\right) \\ P & \text { power }(\mathrm{W}) \\ \eta_{f} & \text { fuel conversion efficiency } \\ \text { BSFC } & \text { brake specific fuel consumption } \\ \eta_{v} & \text { volumetric efficiency } \\ \text { VGT } & \text { variable geometry turbocharger } \\ \text { GDI } & \text { gasoline direct injection } \\ \text { CVT } & \text { continuously variable transmission } \\ Q_{H V} & \text { fuel heating value }(\mathrm{J} / \mathrm{kg}) \\ \text { EAT } & \text { Electrically assisted turbocharger } \\ \text { EC } & \text { Electric compressor } \\ \text { EST } & \text { Electrically split turbocharger } \\ & \end{array}$




\section{References}

1. OECD and International Transport Forum. Reducing Transport Greenhouse Gas Emissions. Trends \& Data 2010; OECD: Copenhagen, Denmark, 2010; pp. 1-94.

2. Department for Business Energy and Industrial Strategy. Annual January Prices of Road Fuels and Petroleum Products. 2013. Available online: https://www.gov.uk/government/statistical-data-sets/oil-and-petroleumproducts-annual-statistics (accessed on 1 January 2017).

3. Alshammari, F.; Karvountzis-Kontakiotis, A.; Pesyridis, A.; Usman, M. Expander Technologies for Automotive Engine Organic Rankine Cycle Applications. Energies 2018, 11, 1905. [CrossRef]

4. Alshammari, F.; Karvountzis-Kontakiotis, A.; Pesyridis, A. Effect of radial turbo-expander design on off-highway vehicle organic Rankine cycle system efficiency. Int. J. Powertrains 2018, 7, 72-93. [CrossRef]

5. Alshammari, F.; Pesyridis, A.; Karvountzis-Kontakiotis, A.; Franchetti, B.; Pesmazoglou, Y. Experimental study of a small scale organic Rankine cycle waste heat recovery system for a heavy duty diesel engine with focus on the radial inflow turbine expander performance. Appl. Energy 2018, 215, 543-555. [CrossRef]

6. Alshammari, F.; Pesyridis, A. Experimental study of organic Rankine cycle system and expander performance for heavy-duty diesel engine. Energy Convers. Manag. 2019, 199. [CrossRef]

7. Alshammari, F.; Karvountzis-Kontakiotis, A.; Pesiridis, A. Radial turbine expander design for organic rankine cycle, waste heat recovery in high efficiency, off-highway vehicles. In Proceedings of the 3rd Biennial International Conference on Powertrain Modelling and Control (PMC 2016), Loughborough, UK, 7-9 September 2016.

8. Karvountzis-Kontakiotis, A.; Pesiridis, A.; Zhao, H.; Alshammari, F.; Franchetti, B.; Pesmazoglou, I.; Tocci, L. Effect of an ORC Waste Heat Recovery System on Diesel Engine Fuel Economy for Off-Highway Vehicles; SAE International: Warrendale, PA, USA, 2017.

9. Crane, D.T.; Jackson, G.S. Optimization of cross flow heat exchangers for thermoelectric waste heat recovery. Energy Convers. Manag. 2004, 45, 1565-1582. [CrossRef]

10. Saidur, R.; Rezaei, M.; Muzammil, W.K.; Hassan, M.H.; Paria, S.; Hasanuzzaman, M. Technologies to recover exhaust heat from internal combustion engines. Renew. Sustain. Energy Rev. 2012, 16, 5649-5659. [CrossRef]

11. Arnaud, L.; Ludovic, G.; Mouad, D.; Hamid, Z.; Vincent, L. Comparison and Impact of Waste Heat Recovery Technologies on Passenger Car Fuel Consumption in a Normalized Driving Cycle. Energies 2014, 7, 5273-5290.

12. Thirouard, M.; Mendez, S.; Pacaud, P.; Chmielarczyk, V.; Ambrazas, D.; Garsi, C.; Lavoisier, F.; Barbeau, B. Potential to Improve Specific Power Using Very High Injection Pressure in HSDI Diesel Engines Frédéric Lavoisier Base engine. SAE Pap. 2009. [CrossRef]

13. Petitjean, D.; Bernardini, L.; Middlemass, C.; Shahed, S.M. Advanced Gasoline Engine Turbocharging Technology for Fuel Economy Improvements. SAE Pap. 2004. [CrossRef]

14. Rose, A. Application of a Continuously Variable Transmission to Engine Boosting and Exhaust Energy Recovery Systems. Ph.D. Thesis, Bath University, Bath, UK, 2013.

15. Hancock, D.; Fraser, N.; Jeremy, M.; Sykes, R.; Blaxill, H. A New 3 Cylinder 1.21 Advanced Downsizing Technology Demonstrator Engine. SAE Pap. 2008, 2008, 776-790.

16. Kleeberg, H.; Tomazic, D.; Lang, O.; Habermann, K. Future Potential and Development Methods for High Output Turbocharged Direct Injected Gasoline Engines Reprinted from: SI Combustion and Direct Injection SI Engine Technology. SAE Pap. 2006. [CrossRef]

17. Wijetunge, R.; Criddle, M.; Dixon, J.; Morris, G. Comparative Performance of Boosting Systems for a HighOutput, SmallCapacity Diesel Engine; STA paper F2004F195; STA: Lubbock, TX, USA, 2004.

18. Chadwell, C.J.; Walls, M. Analysis of a SuperTurbocharged Downsized Engine Using 1-D CFD Simulation. SAE Pap. 2010. [CrossRef]

19. Turner, J.W.G.; Pearson, R.J.; Kenchington, S.A. Concepts for improved fuel economy from gasoline engines. Int. J. Engine Res. 2005, 6, 137-157. [CrossRef]

20. Ford Motor Company. New High Efficiency Four-Cylinder Ford Ecoboost Engine Family Debuts at Frankfurt; Ford Motor Company, 2009; Available online: https://www.greencarcongress.com/2009/09/fordecoboost-20090916. html (accessed on 19 January 2019).

21. Alfa Romeo. Alfa Romeo Technology Innovation: 1750i 200 bhp Turbo Petrol Engine [online]. 2010. Available online: http://www.alfaromeo.co.uk/uk/cmsen/models/alfa_159/pages/alfa-159-motori.aspx?outputXml= true\&CustomResponse $=$ WebCrawler (accessed on 19 January 2019). 
22. MultiAir: The Ultimate Air Management Strategy. Fiat Powertrain Technol. S.p.A. 2009. Available online: http://www.fptmultiair.com/flash_multiair_eng/Cartella\%20Stampa\%20ENG\%20def\%20_3_.pdf (accessed on 15 January 2019).

23. King, J.; Böcker, O. Multiple Injection and Boosting Benefits for Improved Fuel Consumption on a Spray Guided Direct Injection Gasoline Engine. In Proceedings of the FISITA 2012 World Automotive Congress; Springer: Berlin/Heidelberg, Germany, 2013; pp. 229-241.

24. Mercedes-Benz. Direct Injection with Spray-Guided Combustion as a Future Technology for the Spark-Ignition Engine. Available online: https://media.daimler.com/marsMediaSite/en/instance/ko/Thetechnology-of-the-new-direct-injection-petrol-engine-from-Mercedes-Benz-Direct-injection-with-sprayguided-combustion-as-a-future-technology-for-the-spark-ignition-engine.xhtml?oid=9905308 (accessed on 28 November 2019).

25. Roberts, M. Benefits and challenges of variable compression ratio (VCR). SAE Pap. 2003. [CrossRef]

26. Kleeberg, H.; Tomazic, D.; Balazs, A.; Wittek, K.; Balazs, A. Increasing Efficiency in Gasoline Powertrains with a Two-Stage Variable Compression Ratio (VCR) System. SAE Pap. 2013. [CrossRef]

27. Heywood, J.B. Internal Combustion Engine Fundamentals; McGraw-Hill Education: New York, NY, USA, 1988.

28. Schmitt, F. Powerful Turbocharging System for Passenger Car Diesel Engines. MTZ Worldw. 2014, 75, 12-19. [CrossRef]

29. Aina, T.; Folayan, C.O.; Pam, G.Y. Influence of compression ratio on the performance characteristics of a spark ignition engine. Adv. Appl. Sci. Res. 2012, 3, 1915-1922.

30. Leichtfuß, S.; Bühler, J.; Schiffer, H.-P.; Peters, P.; Hanna, M. A Casing Treatment with Axial Grooves for Centrifugal Compressors. Int. J. Turbomach. Propuls. Power 2019, 4, 27. [CrossRef]

31. Swain, D.; Engeda, A. Effect of impeller blade trimming on the performance of a 5.5:1 pressure ratio centrifugal compressor. Proc. Inst. Mech. Eng. Part A J. Power Energy 2014, 228, 602-613. [CrossRef]

32. Omidi, M.; Liu, S.-J.; Mohtaram, S.; Lu, H.; Zhang, H.-C. Improving Centrifugal Compressor Performance by Optimizing the Design of Impellers Using Genetic Algorithm and Computational Fluid Dynamics Methods. Sustainability 2019, 11, 5409. [CrossRef]

33. Alshammari, F. Radial Turbine ExpanderDesign, Modelling and Testing for Automotive Organic Rankine Cycle Waste Heat Recovery. Ph.D. Thesis, Brunel University London, Uxbridge, UK, 2018.

34. Lee, S.P.; Barrans, S.M.; Jupp, M.L.; Nickson, A.K. The Impact of Volute Aspect Ratio on the Performance of a Mixed Flow Turbine. Aerospace 2017, 4, 56. [CrossRef]

35. Jung, H.; Krumdieck, S. Meanline design of a $250 \mathrm{~kW}$ radial inflow turbine stage using R245fa working fluid and waste heat from a refinery process. Proc. Inst. Mech. Eng. Part A J. Power Energy 2016, 230, 402-414. [CrossRef]

36. Agromayor, R.; Nord, L.O. Preliminary Design and Optimization of Axial Turbines Accounting for Diffuser Performance. Int. J. Turbomach. Propuls. Power 2019, 4, 32. [CrossRef]

37. Baets, J.; Bernard, O.; Gamp, T.; Zehnder, M. Design and performance of ABB turbocharger TPS57 with variable turbine geometry. In Proceedings of the IMechE Conference Transactions, London, UK, 3-5 November 1998; Volume 32, p. 3.

38. Ishino, M.; Bessho, A. Mixed-Flow Variable Nozzle Turbine Mixed-Flow Variable Nozzle Turbine, Vol.35, No.3, Special ISSUE: Variable Geometry Turbocharger for Automotive Use. 2000. Available online: http://www.tytlabs.co.jp/english/review/rev353e.html (accessed on 27 January 2019).

39. Pesiridis, A. Issues in the integration of active control turbochargers with internal combustion engines. Int. J. Automot. Technol. 2012, 13, 873-884. [CrossRef]

40. Pesiridis, A. The application of active control for turbocharger turbines. Int. J. Engine Res. 2012, 13, 385-398. [CrossRef]

41. Cravero, C.; De Domenico, D.; Ottonello, A. Numerical Simulation of the Performance of a Twin Scroll Radial Turbine at Different Operating Conditions. Int. J. Rotating Mach. 2019, 2019, 13. [CrossRef]

42. Watson, N.; Janota, M.S. Turbocharging the Internal Combustion Engine; Macmillan: London, UK, 1982.

43. Atac, O.F.; Yun, J.-E.; Noh, T. Aerodynamic Design Optimization of a Micro Radial Compressor of a Turbocharger. Energies 2018, 11, 1827. [CrossRef]

44. Mojaddam, M.; Pullen, K.R. Optimization of a Centrifugal Compressor Using the Design of Experiment Technique. Appl. Sci. 2019, 9, 291. [CrossRef] 
45. Alshammari, F.; Karvountzis-Kontakiotis, A.; Pesyridis, A.; Alatawi, I. Design and study of back-swept high pressure ratio radial turbo-expander in automotive organic Rankine cycles. Appl. Therm. Eng. 2010, 164, 114549. [CrossRef]

46. Alshammari, F.; Karvountzis-Kontakiotis, A.; Pesiridis, A.; Giannakakis, P. Off-design performance prediction of radial turbines operating with ideal and real working fluids. Energy Convers. Manag. 2018, 171, 1430-1439. [CrossRef]

47. Latz, G.; Erlandsson, O.; Skåre, T.; Contet, A.; Andersson, S.; Munch, K. Performance Analysis of a Reciprocating Piston Expander and a Plate Type Exhaust Gas Recirculation Boiler in a Water-Based Rankine Cycle for Heat Recovery from a Heavy Duty Diesel Engine. Energies 2016, 9, 495. [CrossRef]

48. Baines, N.C. Fundamentals of Turbocharging; Concepts NREC: White River Junction, VT, USA, 2005.

49. Arnold, S. Single Sequential Turbocharger: A New Boosting Concept for Ultra-Low Emission Diesel Engines. SAE Pap. 2008. [CrossRef]

50. Stobart, R.; Weerasinghe, R. Heat Recovery and Bottoming Cycles for SI and CI engines-A Perspective. SAE Tech. Pap. 2006. [CrossRef]

51. Pesiridis, A.; Salim, W.S.-I.W.; Martinez-Botas, R. Turbocharger Matching Methodology for Improved Exhaust Energy Recovery. In Proceedings of the 10th International Conference on Turbocharging and Turbochargers, London, UK, 15-16 May 2012.

52. Schmitz, T.N.; Holloh, K.; Juergens, R.; Fleckenstein, G.; Ag, M. Potential of Additional Mechanical Supercharging for Commercial Vehicle Engines. SAE Pap. 1994. [CrossRef]

53. Karvountzis-Kontakiotis, A.; Alshammari, F.; Pesiridis, A.; Franchetti, B.; Pesmazoglou, I.; Tocci, L. Variable Geometry Turbine Design for Off-Highway Vehicle Organic Rankine Cycle Waste Heat Recovery. In Proceedings of the THIESEL 2016 Conference on Thermo-and Fluid Dynamic Processes in Direct Injection Engines, Valencia, Spain, 13-16 September 2016.

54. Matsura, Y.; Nakazawa, N.; Kobayashi, Y.; Ogita, H.; Kawatani, T. Effects of Various Methods for Improving Vehicle Startability. SAE Pap. 1992. [CrossRef]

55. Timoney, S.G. A Review of Ideas for Improving Transient Response in Vehicle Diesel Engines. SAE Pap. 1986. [CrossRef]

56. Hishikawa, A.; Okazaki, Y.; Busch, P. Developments of Variable Area Radial Turbines for Small Turbochargers. SAE Pap. 1988. [CrossRef]

57. Kawamoto, A.; Takahashi, Y.; Koiken, T.; Nakamura, F. Variable Geometry System Turbocharger for Passenger Car Diesel Engine. SAE Pap. 2001. [CrossRef]

58. Hawley, J.G.; Wallace, F.J.; Cox, A.; Horrocks, R.W.; Bird, G.L. Variable geometry turbocharging for lower emissions. Proc. Inst. Mech. Eng. Part D J. Automob. Eng. 1999, 213, 145-159. [CrossRef]

59. Pfluger, F. Regulated two-stage turbocharging-KKK's new charging system for commercial diesel engines. In Proceedings of the Sixth International Conference on Turbocharging and Air Management Systems, London, UK, 3-5 November 1998; pp. 127-141.

60. Saulnier, S.; Guilain, S. Computational Study of Diesel Engine Downsizing Using Two-Stage Turbocharging. SAE Pap. 2004. [CrossRef]

61. Sommerhoff, F.A. Analysis of a twin turbocharger and a single turbocharger concept on a HSDI V6 diesel engine applying engine cycle simulation. In Proceedings of the Seventh International Conference on Turbochargers and Turbocharging, London, UK, 14-15 May 2002; pp. 235-245.

62. Mährle, C.L.W. BMW High Precision Fuel Injection in Conjunction with Twin-Turbo Technology: A Combination for Maximum Dynamic and High Fuel Efficiency. SAE Pap. 2007. [CrossRef]

63. Tashima, S.; Taqdokoro, T.; Okimoto, H.; Niwa, Y. Development of Sequential Twin Turbo System for Rotary Engine. SAE Pap. 1991. [CrossRef]

64. Brüstle, C.; Wagner, J.; Van, K.T.; Burk, K. Turbocharging techniques for sports car engines. In Proceedings of the Fourth International Conference on Turbocharging and Turbochargers, London, UK, 22-24 May 1990; pp. 317-328.

65. Qian, Y.; Zhang, Z.; Deng, K. Development of a Three-Phase Sequential Turbocharging System with Two Unequal-Size Turbochargers. Int. J. Rotating Mach. 2012, 2012, 8. [CrossRef]

66. Bhinder, F.S. Supercharging Compressors-Problems and Potential of the Various Alternatives. SAE Pap. 1984. [CrossRef] 
67. Stone, R. Exploitation of Full-Toroidal CVT Technology to a Centrifugal Supercharger for Radical Engine Downsizing Applications. In Proceedings of the Ninth International Symposium on Innovative Automotive Transmissions and Hybrid \& Electric Drives, Novi, MI, USA, 15-18 May 2010.

68. Stone, C. The efficiency of Roots compressors and compressors with fixed internal compression. Proc. Inst. Mech. Eng. Part A Power Process Eng. 1988, 202, 199-205. [CrossRef]

69. Eaton Corporation. TVS Roots-Type Superchargers; Eaton Industrial Systems pvt, Ltd.: Maharashtra, India, 2011.

70. Hori, M.; Ikeya, N.; Takabe, S.; Miyagi, Y. Examinations of a Lysholm Compressor's performance and the engine performance supercharged by the Lysholm Compressor. In Proceedings of the Sixth International Conference on Turbocharging and Air Management Systems, London, UK, 3-5 November 1998; pp. 115-126.

71. Joyce, M.J. Jaguar's supercharged 6-cylinder engine. In Proceedings of the Fifth International Conference on Turbocharging and Turbochargers, London, UK, 7-9 June 1994; pp. 127-137.

72. Stone, R. Introduction to Internal Combustion Engines, 3rd ed.; Macmillan Publishers Ltd.: Basingstoke, UK, 1999.

73. Richter, H.; Hemmerlein, N. Experiences with supercharging the Porsche 944 engine. In Proceedings of the Fourth International Conference on Turbocharging and Turbochargers, London, UK, 22-24 May 1990; pp. 283-287.

74. Tomita, T.; Ikeya, N.; Ishihara, D.; Kondoh, N.; Ohkita, A. Hybrid Charging System for Heavy Duty Diesel Engines. SAE Pap. 1991. [CrossRef]

75. Samuel, E.O. TSI Maximum power with minimum consumption. Volkswagen Uganda. Available online: https:// volkswagenuganda.wordpress.com/2015/03/20/tsi-maximum-power-with-minimum-consumption (accessed on 28 November 2019).

76. Whitworth, B. Doppelgänger. Automot. Eng. 2006, 31, 37-38.

77. Cantore, G.; Mattarelli, E.; Fontanesi, S. A New Concept of Supercharging Applied to High Speed DI Diesel Engines. SAE Pap. 2001. [CrossRef]

78. Mattarelli, E. Comparison among different 2-Stage Supercharging systems for HSDI Diesel engines. In Proceedings of the Ninth International Conference on Engines and Vehicles, Naples, Italy, 13-18 September 2009.

79. Ricardo, M.B.; Apostolos, P.; Yang, M.Y. Overview of boosting options for future downsized engines. Sci. China Technol. Sci. 2011, 54, 318-331. [CrossRef]

80. Ulrich, H.; Kruiswyk, R.W. Diesel Engine Waste Heat Recovery Utilizing Electric Turbocompound Technology; U.S. Department of Energy Office (DOE) of Scientific and Technical Information (OSTI): Oak Ridge, TN, USA, 2005. [CrossRef]

81. Lee, W.; Schubert, E.; Li, Y.; Li, S.; Bobba, D.; Sarlioglu, B. Overview of Electric Turbocharger and Supercharger for Downsized Internal Combustion Engines. IEEE Trans. Transp. Electrif. 2017, 3, 36-47. [CrossRef]

82. Villegas, J.; Gao, B.; Svancara, K.; Thornton, W.; Parra, J. Real-time Simulation and Control of an Electric Supercharger for Engine Downsizing. In Proceedings of the 2011 IEEE Vehicle Power and Propulsion Conference, Chicago, IL, USA, 6-9 September 2011; pp. 1-6.

83. Tavčar, G.; Bizjan, F.; Katras, T. Methods for improving transient response of diesel engines-influences of different electrically assisted turbocharging topologies. J. Automob. Eng. 2011, 225, 1167-1185. [CrossRef]

84. Baderman, H. Boosting Methods in Highly Downsized Diesel Engines; Imperial College: London, UK, 2013.

85. Nishiwaki, K.; Iezawa, M.; Tanaka, H.; Goto, T.; An, B. Development of High Speed Motor and Inverter for Electric Supercharger. SAE Tech. Pap. 2013, 2. [CrossRef]

86. VanDyne, E.; Brinks, B.T.; Riley, M.B.; Brown, J. Super-Turbocharger Having a High Speed Traction Drive and a Continuously Variable Transmission. U.S. Patent Application 12/536,421, 11 February 2010.

87. Brockbank, C. Application of a variable drive to supercharger \& turbo compounder applications. SAE Pap. 2009. [CrossRef]

88. Wallace, F. Operating Characteristics of Compound Engine Schemes for Traction Purposes Based on Opposed Piston Two-Stroke Engines and Differential Gearing. Proc. Inst. Mech. Eng. 1963, 177, 64-85.

89. Wallace, F.J.; Tarabad, M.; Howard, D. The Differential Compound Engine-A New Integrated Engine Transmission System Concept for Heavy Vehicles. Proc. Inst. Mech. Eng. Part A J. Power Energy 1983, 197, 209-218. [CrossRef] 
90. Wallace, F.J. On-road performance of two alternative engine transmission systems for heavy vehicles. In Proceedings of the Fourth International Conference on Turbocharging and Turbochargers, London, UK, 22-24 May 1990; pp. 99-112.

91. Patterson, A.T.C.; Tett, R.J.; McGuire, J. Exhaust heat recovery using electro-turbogenerators. SAE Tech. Pap. 2009, 4970. [CrossRef]

92. Cummins Turbo Technologies, Turbocompound System. Available online: http://www.holset.co.uk/mainsite/ files/2_5_1_3-turbocompound\%20system.php (accessed on 10 January 2019).

93. Walsham, B.E. Alternative turbocharger systems for the automotive diesel engine. In Proceedings of the Fourth International Conference on Fourth International Conference on Turbocharging and Turbochargers, London, UK, 22-24 May 1990; pp. 39-50.

94. Wallace, F.J. The ultimate performance potential of compounded diesel engines for heavy vehicles. In Proceedings of the Sixth International Conference on Turbocharging and Air Management Systems, London, UK, 3-5 November 1998; pp. 253-268.

95. Panting, J.; Pullen, K.R.; Martinez-Botas, R.F. Turbocharger motor-generator for improvement of transient performance in an internal combustion engine. Proc. Inst. Mech. Eng. Part D J. Automob. Eng. 2001, 215, 369-383. [CrossRef]

96. Katrašnik, T.; Rodman, S.; Trenc, F.; Hribernik, A.; Medica, V. Improvement of the Dynamic Characteristic of an Automotive Engine by a Turbocharger Assisted by an Electric Motor. J. Eng. Gas Turbines Power 2003, 125, 590. [CrossRef]

97. Hopmann, U.; Algrain, M.C. Diesel Engine Electric Turbo Compound Technology. SAE Pap. 2003. [CrossRef]

98. Millo, F.; Mallamo, F.; Pautasso, E.; Mego, G.G. The Potential of Electric Exhaust Gas Turbocharging for HD Diesel Engines. SAE Tech. Pap. 2006. [CrossRef]

99. Hountalas, D.T.; Katsanos, C.O.; Lamaris, V.T. Recovering Energy from the Diesel Engine Exhaust Using Mechanical and Electrical Turbocompounding. SAE Pap. 2007. [CrossRef]

100. Aeristech. Breakthrough Technology; Aeristech Ltd.: Warwickshire, UK, 2010; Available online: https: //www.aeristech.co.uk/breakthrough-technology/ (accessed on 28 November 2019).

101. Pesiridis, A. Automotive Exhaust Emissions and Energy Recovery; Nova Science Pub Inc.: Hauppauge, NY, USA, 2014.

102. Odaka, M.; Koike, N.; Hijikata, Y.; Miyajima, T. Energy Regeneration of Heavy Duty Diesel Powered Vehicles. SAE Pap. 1998. [CrossRef]

(C) 2019 by the authors. Licensee MDPI, Basel, Switzerland. This article is an open access article distributed under the terms and conditions of the Creative Commons Attribution (CC BY) license (http://creativecommons.org/licenses/by/4.0/). 